\title{
Changes in tropical Atlantic interannual variability from a substantial weakening of the meridional overturning circulation
}

Article

Accepted Version

Polo, I., Dong, B. W. and Sutton, R. T. (2013) Changes in tropical Atlantic interannual variability from a substantial weakening of the meridional overturning circulation. Climate Dynamics, 41 (9-10). pp. 2765-2784. ISSN 1432-0894 doi: https://doi.org/10.1007/s00382-013-1716-x Available at https://centaur.reading.ac.uk/32611/

It is advisable to refer to the publisher's version if you intend to cite from the work. See Guidance on citing.

To link to this article DOI: http://dx.doi.org/10.1007/s00382-013-1716-x

Publisher: Springer

All outputs in CentAUR are protected by Intellectual Property Rights law, including copyright law. Copyright and IPR is retained by the creators or other copyright holders. Terms and conditions for use of this material are defined in the End User Agreement.

www.reading.ac.uk/centaur 
Central Archive at the University of Reading

Reading's research outputs online 
CHANGES IN TROPICAL ATLANTIC INTERANNUAL VARIABILITY FROM A SUBSTANTIAL WEAKENING OF THE MERIDIONAL OVERTURNING CIRCULATION

\author{
Irene Polo \\ Buwen W. Dong \\ Rowan T. Sutton
}

NCAS-Climate, Department of Meteorology, University of Reading, UK PO Box 243, Earley Gate, Reading RG6 6BB, U.K.

Corresponding author: Irene Polo

Email: i.polo@ reading.ac.uk

Phone: +44 01183786016 


\begin{abstract}
In response to a substantial weakening of the Atlantic Meridional Overturning Circulation (AMOC) - from a coupled ocean-atmosphere general circulation model experiment - significant changes in the interannual variability are found over the tropical Atlantic, characterized by an increase of variance (by $\sim 150 \%$ ) in boreal late spring-early summer and a decrease of variance (by $\sim 60 \%$ ) in boreal autumn. This study focuses on understanding physical mechanisms responsible for these changes in interannual variability in the tropical Atlantic. It demonstrates that the increase of variability in spring is a consequence of an increase in the variance of the El Niño-Southern Oscillation, which has a large impact on the tropical Atlantic via anomalous surface heat fluxes. Winter El Niño (La Niña) affects the eastern equatorial Atlantic by decreasing (increasing) cloud cover and surface wind speed which is associated with anomalous downward (upward) short wave radiation and reduced (enhanced) upward latent heat fluxes, creating anomalous positive (negative) Sea Surface Temperature (SST) anomalies over the region from winter to spring. On the other hand, the decrease of SST variance in autumn is due to a deeper mean thermocline which weakens the impact of the thermocline movement on SST variation. The comparison between the model results and observations is not straightforward owing to the influence of model biases and the lack of a major MOC weakening event in the instrumental record. However, it is argued that the basic physical mechanisms found in the model simulations are likely to be robust and therefore have relevance to understanding tropical Atlantic variability in the real world, perhaps with modified seasonality.
\end{abstract}

Keywords: Atlantic Meridional Overturning Circulation, Tropical Atlantic Interannual Variability 


\section{Introduction}

Interannual variability in the tropical oceans exhibits decadal-multidecadal fluctuations in the observational records. Observations showed that the characteristics of El Niño-Southern Oscillation (ENSO), the most important mode of interannual variability with world-wide impacts (Bjerknes, 1969; Philander, 1990) that takes place over the tropical Pacific, changed in the mid-1970s. These changes are characterized by longer periodicity, stronger asymmetry between El Niño and La Niña events, more central Pacific Niño-type events with eastward propagation and with more active thermocline and non-linear feedbacks (Federov and Philander, 2000; Wang and An, 2002; An, 2008), associated with a change in the equatorial mean stratification (Moon et al., 2004) after the mid-1970s. Together with enhanced ENSO variability in the last few decades, evidence of a weakening of the Walker Circulation is also reported by Vecchi et al. (2006) and more recently by Tokinaga et al. (2012) consistent with subsurface temperature changes that were characterized by a warming in the east and a cooling in the west around the thermocline depth in the tropical Pacific with a reduced thermocline slope (Moon et al., 2004).

Interannual Tropical Atlantic Variability (TAV) has a leading mode in boreal summer over the equatorial Atlantic known as Equatorial mode or Atlantic Niño (Zebiak et al., 1993) with similar physical mechanisms but smaller amplitude than its Pacific counterpart (Keenlyside and Latif, 2007; Polo et al., 2008). Conversely, the Sea Surface Temperature (SST) zonal gradient over the equatorial Atlantic shows a decreasing trend from the 50s, associated with a deeper thermocline and an increase of precipitation and reduced zonal winds over the east equatorial Atlantic (Tokinaga and Xie, 2011). They have shown (figure 1 in Tokinaga and Xie, 2011) a decrease of the zonal SST gradient interannual variability in the last few decades relative to the period 1955-1970.

Regardless the different behaviours of the decadal-multidecadal modulation of the interannual variability in the two tropical basins, there is an evidence of increased connection between Atlantic and Pacific Niños since late 60s (Polo et al., 2008; Rodriguez-Fonseca et al., 2009; Martin-Rey et al., 2012). This increased relationship in the late 60s seems to concur with the phase change of the Atlantic Multidecadal Oscillation (AMO) (Rodriguez-Fonseca et al., 2012), as it also modulates ENSO teleconnections with west African monsoon (Rodriguez-Fonseca et al., 2010) and ENSO influence on the precipitation over Europe (Lopez-Parages and Rodriguez-Fonseca, 2012).

Thus, one important factor that could modulate the tropical Atlantic-Pacific relationship is the AMO. The AMO pattern reflects an interhemispheric thermal contrast and it is a leading pattern of multidecadal SST variability which affects the global climate (Knight et al., 2005; Sutton and Hodson, 2007; Dong et al., 2005). In particular, model studies have demonstrated how the AMO patterns are able to change the interannual variability over the Equatorial Pacific (Dong et al., 2006).

Observations have revealed a negative AMO phase in the 60-80s followed by a change to positive phase from mid 1990s (Knight et al., 2005). The latter warming over the North Atlantic was partly caused by a strengthened Atlantic Meridional Overturning Circulation (AMOC) and northward heat transport of the Atlantic Ocean (Robson et al., 2012). Other observational changes in the heat content from 80s over the North Atlantic have been reported and suggested to be related to a change in the AMOC (Curry et al., 2003; Zhai and Sheldon, 2012). 
AMO-like Atlantic dipolar SST pattern and thus to an associated anomalous shift of the InterTropical Convergence Zone (ITCZ) (Vellinga and Wood, 2002; Dong and Sutton, 2002a; Dahl et al., 2005; Zhang and Delworth, 2005; Dong and Sutton, 2007, referred to as DS07; Haarsma et al., 2008; Laurian et al., 2009; Lu and Dong, 2008; Chang et al., 2008 among others, see also figure 3).

Simulation of a disruption of the AMOC by imposing massive fresh water over the North Atlantic, experiment referred to as "water hosing", produces a negative AMO-like signal. The adjustment of the system to the equilibrium state occurs, at least, in two states: a fast atmospheric adjustment from the North Atlantic SST anomalies, which includes a change in the North Pacific via anomalous westerly winds (Dong and Sutton, 2002a; Wu et al., 2008; Chiang et al., 2008) and a slow oceanic adjustment, which seems to be the responsible for the major warming over the equatorial and South Tropical Atlantic (Chang et al., 2008; Wu et al., 2008; Wen et al., 2010) tightly related to the anomalous northward return flow over the western boundary (reverse of the North Brazil Current, NBC) which permits the penetration of the subsurface warming over the north tropical Atlantic into the equatorial thermocline (Jochum and Malanotte-Rizzoli, 2001; Hazeleger and Drijfhout, 2006; Chang et al., 2008; Wen et al., 2010). Besides, similar to the SST anomalies over the extratropics, the dipolar SST over the Atlantic is explained in part by WindEvaporation-SST feedback (WES; Chang et al., 1997), intensifying the anomalous northeasterly winds and its thermodynamic interaction within the oceanic mixed layer (Chiang et al., 2008). In addition, Laurian et al., (2009) have suggested that reduced water vapor content is acting as the main feedback which is necessary to account for the surface cooling over North Atlantic.

The southward ITCZ-shift appears as a response of the anomalous tropical SST gradient (Vellinga and Wood, 2002; Wu et al., 2008). The associated change of the SST and tropical convection especially over the Caribbean SeaAtlantic Warm Pool (AWP, Wang and Enfield 2001), has an impact over the eastern tropical Pacific via diabatic heating (Sutton and Hodson, 2007; Dong and Sutton, 2002a; DS07) which substantially reduces the equatorial Pacific annual cycle. The atmospheric bridge mechanism to explain the Atlantic impact onto the equatorial Pacific, by inducing a large-scale anticyclonic circulation pattern together with northerly trade wind intensification crossing the Panama strait (Xie et al., 2007; Dong et al., 2006; Wang et al., 2010) is in agreement with most of the studies modelling the disruption of the AMOC: The intensification of the trade winds over the northern tropical Pacific drives to southward ITCZ displacement and the generation of the meridional SST anomaly (Vellinga and Wood, 2002; Zhang and Delworth, 2005; DS07; Timmermann et al., 2007; Wu et al., 2008; van Oldenborgh et al., 2009), although the mean state changes in the Pacific are sensitive and nonlinear with respect to the magnitudes of AMOC changes (van Oldenborgh et al., 2009; DS07).

In GCMs, a reduction of the equatorial Pacific annual cycle occurs together with an intensification of the ENSO variance (Guilyardi, 2005). From a weakening AMOC, some authors have found a reduction of the tropical Pacific variability (Timmermann et al., 2005) due to oceanic teleconnection; while other works have indicated the increase of the ENSO variance (DS07; Timmermann et al., 2007) due to fast atmospheric teleconnection. The most plausible explanation for the change of equatorial Pacific variability due to a reduction of AMOC was exposed by DS07. They pointed out anomalous westerly winds over central Pacific from August to February, causing an eastward extension to the warm pool. Background changes leads to an eastward shift of the zonal wind anomalies associated with El Niño events and an increase of variance. Besides, from a multi-model study, Timmermann et al. (2007) have also associated the meridionally symmetric thermal background state, with the weakening of the annual cycle in the 
eastern equatorial Pacific and a subsequent intensification of ENSO variability due to nonlinear interactions.

The influence of ENSO onto the TAV has been investigated by different authors. The major effect has been found on the SST over the North Tropical Atlantic (Nobre and Shukla, 1996; Enfield and Mayer, 1997; Saravanan and Chang 2000). One of the mechanisms proposed is through the Pacific North American (PNA) teleconnection pattern (Nobre and Shukla, 1996). The winter ENSO could also impact the next spring North Tropical Atlantic throughout largescale subsidence resulting in anomalous SST through anomalous surface heat fluxes (Enfield and Mayer, 1997; Saravanan and Chang, 2000). Additionally, changes in the SST in the North could, in turn, induce a WES feedback which shifts the Atlantic ITCZ (Saravanan and Chang, 2000). Other authors have suggested that ENSO can change zonal wind stress over the west equatorial Atlantic via equatorial wave dynamics which eventually is able to trigger the development of Atlantic Niño (Latif and Barnett, 1995; Munnich and Neelin, 2005). From GCM studies, changes in convection over the Amazon basin and western equatorial Atlantic can be explained in part by anomalous moisture advection and vertical stability changes associated with tropospheric warming related to Niño (Su and Neelin, 2002; Neelin et al., 2003). Chiang et al. (2000) found how ENSO impacts the Atlantic ITCZ through Walker circulation in a non stationary manner, resulting from a nonlinear relationship between SST and convection in the eastern Equatorial Pacific. Interestingly significant impacts over the deep tropics and particularly impacting the Atlantic Niño variability seem to be very inconsistent (Chang et al., 2006; Lübbecke and McPhaden, 2012; De Almeida and Nobre, 2012). Chang et al (2006) have suggested that the impact of ENSO onto Atlantic Niños is very much dependent on the actual equatorial Atlantic mean state, in such a way that the mean thermocline over the eastern equatorial Atlantic is crucial to create SST variance through Bjerknes feedback, regardless of how strong ENSO could be (Chang et al., 2006). Recently, Lübbecke and McPhaden (2012) have argued that ocean dynamics is also playing a role in the inconsistent relationship between ENSO and Atlantic Niño: the wave adjustment from offequatorial wind stress curl could be counteracting the initiation of an equatorial event. Finally, another source of variability of the equatorial Atlantic has been pointed out (Richter et al., 2013): ocean advection from the subtropical Atlantic could be playing a role in developing a particular type of Atlantic Niños, which add more complexity to the teleconnections impacting TAV.

Regarding changes in the TAV, similar experiments simulating a weakening of the Atlantic MOC have found a disruption of the equatorial Atlantic interannual variability mainly due to changes in the stratification (Haarsma et al., 2008). In particular, a deepening of the eastern equatorial thermocline makes SST unaffected by thermocline variations, thus, heat budget reveals the reduction of the vertical entraintment of cold water in the mixed layer. This mechanism is important for the Atlantic Niño or Equatorial mode while the cross-equatorial SST gradient or Meridional mode appears to be not significantly modified by a change in AMOC (Haarsma et al., 2008). However, the Haarsma et al's experiment is constrained to the Atlantic basin and it does not consider global influences. In contrast, DS07's experiments consider the global coupled system and therefore global teleconnections but they did not investigate the changes in the TAV. In this study we want to fill this gap by investigating the change of TAV in the water hosing experiment with a global coupled atmosphere ocean circulation model.

In this study we attempt to examine the modulation of the tropical interannual variability by a weakening of the AMOC and therefore by an AMO pattern. The question we like to address is whether a significant weakening AMOC leads to changes in the tropical variability and, more precisely, to changes in the TAV and the tropical AtlanticPacific interannual relationship. Specifically, we will analyse the "water hosing experiment" and the control 
experiment of the HadCM3 model in order to understand: i) what are the main changes in the global background associated with anomalous freshwater perturbations ii) what are the changes in the annual and seasonal cycle over the tropical Atlantic iii) How does the interannual TAV change and finally iv) how does the connection between Atlantic Niños and Pacific Niños change.

The manuscript is organized as follows; section 2 describes the model used and the methodology. Main results are in section 3. Firstly the global background changes and the seasonal cycle over the equatorial Atlantic are analysed. The changes in the tropical Pacific interannual variability will be summarized with our findings and the available literature, followed by a description of the changes in the TAV. A discussion in relation to the connection between basins and some observed features will be presented in section 4 and finally the main conclusions are summarized in section 5 . 


\section{Model and Methods}

\subsection{The model}

The third version of the Hadley Centre Coupled Ocean-Atmosphere General Circulation Model (HadCM3; Gordon et al., 2000) is used in this work. The horizontal resolution is 2.5 x 3.75 latitude-longitude with 19 vertical levels for the atmospheric component and $1.25 \times 1.25$ horizontal resolution and 20 levels for the oceanic component. The ocean component uses a scheme to parameterize horizontal mixing of tracers with a variable thickness diffusion parameterization (Wright 1997). Near-surface vertical mixing is parameterized partly by a Kraus-Turner mixed layer scheme for tracers (Kraus and Turner 1967), and a K-theory scheme (Pacanowski and Philander 1981) for momentum. The sea ice model uses a simple thermodynamic scheme including leads and snow cover. Ice is advected by the surface ocean current only. The control run uses preindustrial boundary conditions. The model does not require flux adjustments to maintain a stable climate.

\subsection{The experiment}

A "water hosing experiment", as a disruption of the AMOC by adding fresh water flux of $1 \mathrm{~Sv}$ for 100 years to the North Atlantic Ocean has been performed. The hosing flux is applied uniformly over the Atlantic between 50-70N. The external fresh water flux is then switched off after model year 100 and integration continues. This experiment does not employ salinity compensation (see DS07 for more details). A parallel control run of 200 years is performed started from the same initial conditions as the water hosing experiment. The decrease in the AMOC is caused by the low-salinity cap over the north Atlantic that prevents sinking and formation of deep water. In this work, we analyse the 1Sv experiment described by DS07 (to notice this anomaly is not comparable with glacial meltwater, instead it gives us a strong signal to noise ratio), in which the model finds a quasi-equilibrium four decades after the hosing is imposed (figure 1 in DS07). Therefore, all the analysis of the differences between the water hosing experiment and the control run has been performed for the last 160 years of the runs in order to highlight the characteristics of the two different stable climates.

The control run and the water hosing experiment from the HadCM3 model has been successfully used for different studies involving the AMOC variability and impacts; In particular Dong and Sutton (2002a) explored the fast adjustment from a substantial weakening of the AMOC, Dong and Sutton (2005) analysed the multidecadal variability of the AMOC, DS07 investigated the impacts of an anomalous AMOC onto the tropical pacific variability. In relation to the extratropical impacts, Brayshaw et al (2009) and Woollings et al., (2012) investigated changes in the subtropical jet and storm tracks under a weakening of the AMOC.

\subsection{Model performance in the control simulation}

The control run simulates an AMOC with a maximum over 30-60N at 900-1000m of $\sim 17-18 \mathrm{~Sv}$ (not shown), which is consistent and in agreement with other state-of-the-art models and the latest observations (Robson et al, 2012; Willis, 2010). The AMOC over $26 \mathrm{~N}$ is $\sim 14-15 \mathrm{~Sv}$ (not shown), which is weak compared with observations from the RAPID-array (Cunningham et al., 2007; Balan Sarojini et al., 2011) and the MOVE-array (Send et al., 2011). 
The seasonal cycle of the observed SST and the HadCM3 model bias over the equatorial Atlantic are displayed in figure 1. Despite the SST bias of the coupled model, that over the upwelling areas can reach more than 4C (figure 1b), the mean SST is in the range of the state-of-the-art models (Collins et al., 2001, Tett et al., 1997). In particular, over the equatorial Atlantic a reversed zonal SST gradient and a strong warm bias in the east is a common feature of most of the CMIP-3 models (Richter and Xie, 2008).

The SST bias over the equatorial Atlantic has been related to several processes; the complex land-sea interation in the Atlantic basin, the oceanic coarse horizontal resolution and the unadequate modelled alongshore winds for reproducing not enough coastal upwelling and northward transport (Grodsky et al., 2012) as well as problems in simulating zonal winds at the equator due to a deficit of Amazon rainfall (Collins et al., 2006, Large and Danabasoglu, 2006; Chang et al., 2007; Richter and Xie, 2008) and the problems associated with the poor simulation of the stratocumulus clouds and its feedbacks (Mechoso et al., 1995; Grodsky et al., 2012). The problems of the coupled models in simulating the seasonal cycle could induce a wrong interannual variability (Breugem et al., 2006).

In HadCM3, the simulation compared with the observations exhibits the following characteristics in the tropics (not shown): the coastal upwelling in the eastern Atlantic and Pacific is substantially reduced. In the Tropical Atlantic basin, the upwelling over the Angola/Benguela front is reduced from MAM to JJA (>3C), while, the bias over the equatorial Atlantic is stronger in JJA $(>4 \mathrm{C})$ and in the eastern part of the basin. In the Tropical Pacific the bias along the South America coast is above $2 \mathrm{C}$ along the year with a cooling below $2 \mathrm{C}$ in a narrow band along the equator from $160 \mathrm{E}$ to $120 \mathrm{~W}$. Interestingly, the equatorial Pacific shows a zonal dipolar pattern inducing a reduced east-west slope of the thermocline. However, Atlantic basin shows a reduced slope of the equatorial thermocline in SON and DJF, while in JJA the thermocline shows a nearly flat structure and in MAM the thermocline has a reversed slope compared with the observations. Heat content is substantially reduced along the year in comparison with the observations over the Indian Ocean, the Eastern American coast including the AWP, and the western African coast and the equatorial Atlantic, which in part explain the reduced equatorial and alongshore SST upwelling.

\subsubsection{Interannual variability in the tropical Pacific}

Regarding the tropical interannual variability, the HadCM3 simulates realistic Pacific Niños (Collins et al., 2001; Joseph and Nigam 2006; Spencer et al., 2007). The HadCM3 El Niño is realistic in the strength, frequency and phase locking to the annual cycle. However, the SST anomalies associated with ENSO exhibit a westward extension (Collins et al., 2001; Spencer et al., 2007). This noticeable feature enhances El Niño-Teleconnections (Collins et al., 2001). This enhanced teleconnection associated with El Niño implies a tropospheric warming over the whole tropical belt, as well as precipitation anomalies along the tropics. The simulated El Niño in HadCM3, as most of the state-ofthe-art models, has more eastern mode Niños-type than central mode Niños-type, however there is an evidence of multidecadal change in the type of Niño in a long-run of HadCM3 (Guilyardi, 2005). Multidecadal modulation of the ENSO activity has been also reported by Chen et al. (2010) associated with its connection with the summer Asian monsoon and explained by changes in the AMO.

2.3.2 Interannual variability in the tropical Atlantic

Concerning the TAV, Breugem et al (2006) showed how the biases in the zonal mode in the state-of-the-art models 
are too strong to assess changes in a future climate. In particular, the SST variance of the equatorial Atlantic in HadCM3 is very low compared with other CMIP-3 models and observations, and is presented in a delayed season (SON) with respect to the observations. Despite the wrong seasonality and the low amplitude, the HadCM3 model simulates Atlantic Niños with ocean-atmosphere feedbacks similar to the observations.

Figure 2 shows the composite maps of the Atl3 index (SST averaged over the region 20W-0E; 3N-3S see box in figure 2a) for the relevant season August-September-October (ASO) for different variables; SST, precipitation, wind stress and Ocean Heat Content (OHC). This mode exhibits the Atlantic Niño characteristics. Atlantic Niños (Niñas) are preceded by anomalous positive (negative) $\mathrm{OHC}$ and decreased (increased) wind stress over the eastern part of the basin and it is associated with more (less) rainfall and surface wind convergence (divergence) over the equator in ASO (figure 2b) up to NDJ (not shown). The Atlantic Niño develops from Angola/Benguela coast in spring and reaches the equator in boreal summer-autumn (Figure 2). Similar pattern have seen in the observations (Keenlyside and Latif, 2007; Polo et al., 2008) although with different seasonality. These similar characteristics are for instance: i) the initiation of the mode starts with anomalous wind over the equator and alongshore Angola/Benguela region. ii) The Bjerknes feedback is operating in boreal autumn (see also section 3.2.2 and figure 11). iii) The termination of the mode can be related to Kelvin wave propagation as the $\mathrm{OHC}$ anomalies propagate eastward from NDJ to the following spring (not shown).

Since the annual cycle is tightly associated with the interannual variability, in the next section the change in the background state as well as the changes in tropical variability from an AMOC collapse will be described. 


\section{Impacts of a substantial weakening AMOC on mean climate and interannual variability}

\subsection{Main changes in the background and the equatorial seasonal cycle}

The changes in the background state are in the line of previous works (Vellinga and Wood, 2002; Dong and Sutton 2002a; Zhang and Delworth, 2005; Dahl et al., 2005; Stouffer et al., 2006; DS07; Timmermann et al., 2007; Chang et al., 2008; Wu et al., 2008). In response to the weakening of the AMOC significant changes in the climate system, from the deep ocean motions (Figure 3e) up to the circulation in the upper troposphere (Figure 3a) occur. Since these changes have been already reported in previous works, here we briefly summarise in the next subsection the main changes illustrated in figure 3 , followed by the description of the main changes in the equatorial Atlantic.

\subsubsection{Changes in the mean state}

From the hosing experiment, the ocean circulation in the Atlantic is highly modified and almost the whole circulation is weaken (figure 3e), the highest modification occurs in the ocean interior $(600-1200 \mathrm{~m})$ at $30 \mathrm{~N}-60 \mathrm{~N}$, where the location of the fresh water anomaly is imposed, but also over the $10 \mathrm{~N}$ around $300 \mathrm{~m}$. According to Chang et al (2008), the anomalous closed northern branch of the Subtropical Cells (STC) of the experiment (figure 3e contour lines) is key elements for the noticeable warming of the southern Atlantic Ocean via NBC reversion mechanism.

A striking result in the Atlantic basin is the dipolar SST pattern: a cooling over the North Atlantic and warming over the South Atlantic (Figure 3c). The cooling is related to a change in the density anomalies which propagates along the American coast in the first decade (Dong and Sutton, 2002a). Wu et al (2008) have attributed the cooling in higher latitudes to a southward extension of the sea-ice while over subpolar regions cooling is associated with intensification of westerly winds (figure 3b). The enhancement of the trade winds over the north Tropical Atlantic cools the region and, throughout WES feedback, warms the west equatorial Atlantic in the last part of the year (not shown). Warming starts to be important over the equatorial Atlantic when the thermocline has deepened enough (not shown) to reduce entrainment. Dipolar SST pattern induces a southward ITCZ-shift with cross-equatorial winds (Figure 3b) and northeasterly wind crossing the Panama strait also displacing the ITCZ over the eastern Tropical Pacific (Figure 3b). Diabatic heating induces anomalous convergence in upper levels over the AWP and two anticyclonic features straddling at the equator over the eastern equatorial Pacific (figure 3a). The change in the Walker circulation is a main characteristic which covers the whole equatorial belt. The changes in the extra-tropics are equivalent barotropic over the Atlantic and Pacific basins (Figure 3a-b) associated with a cooling and a wavenumber-1 teleconnection pattern. The cooling over the northern hemisphere is consistent with the anomalous negative heat content, while the warming (cooling) over 0-20N (20S-0) in the Pacific is due to anomalous Ekman pumping (DS07).

\subsubsection{Changes in the equatorial seasonal cycle}

Figure 4 shows the seasonal cycle for different variables of the equatorial Atlantic associated with the control experiment (Figure 4a-c) and their differences between water hosing experiment and the control run (Figure 4d-f). 
central basin in August-September (Figure 4b) with the shallow thermocline from July to November (figure 4a), being tightly associated with an enhancement of meridional winds and the ITCZ-shift (figure 4c). The cold tongue appears to develop from west to east along the equator (figure $4 \mathrm{~b}$ and is delayed by two months with respect to the observations where it occurs mainly in the late-spring to early autumn (Okumura and Xie, 2004; Xie and Carton, 2004).

In contrast, the shallow thermocline in the water hosing experiment is found from March to July and the cold tongue over the equatorial Atlantic is pronounced from May to August (not shown) but less intense than in the control run. This weak cold tongue in the water hosing experiment is associated with strong precipitation all year round in the equatorial Atlantic (not shown).

Differences between the water hosing experiment and the control show considerably changes in the seasonal cycle. The heat content anomalies show a deep mean thermocline all year round with a maximum in spring. This leads to an increased tilt of the already reversed thermocline (in comparison with the observations) (figure $4 \mathrm{~d}, \mathrm{e}$ ). The cold season occurs in May-August and it spreads eastward from 40W in February to 0E in May-June, and it is associated with anomalous westerlies and reduced precipitation. Warming in summer-autumn is associated with enhanced precipitation related to the southward-shift of the ITCZ.

Since the anomalous Walker circulation is able to connect the Indo-Pacific and Atlantic Ocean basins (figure 3a), it is expected that seasonal cycles of the equatorial Pacific and Atlantic are connected in the water hosing experiment. The anomalous divergent circulation (not shown) suggests strong seasonality: in particular in JJA season, subsidence over North Tropical Atlantic, western equatorial Atlantic and the Indian continent occurs together with ascending motions over the central Pacific and eastern equatorial Atlantic. In the following season SON, the ascending branches are situated over the central-eastern Atlantic and the central Pacific with descending motions over the AWP and the Indo-Pacific warm pool. This is consistent with a warmer SST and anomalous surface wind convergence over central Pacific from June to December (figure 5 in DS07) as well as a warming, anomalous surface westerly winds and convergence over equatorial Atlantic from September to December (figure 4d-f).

\section{$\underline{3.2 \text { Changes in Tropical Interannual Variability }}$}

In this section we describe the interannual variability changes due to the weakening of AMOC. In the first subsection, the interannual variability over the Tropical Pacific is described as a summary of previous works. The second section is devoted to remark the important changes in the TAV.

\subsubsection{Enhanced tropical Pacific Interannual variability}

The changes in the tropical Pacific variability due to a weakening AMOC in HadCM3 were studied in DS07 and additionally compared with more models experiments by Timmermann et al (2007). Figure 5a shows the annual cycle of the Niño3 index. The seasonal evolution of this index in the control run follows that based on observations. However there is a reduction of the annual cycle in the experiment, also reported in DS07. The variability of Niño3 index (figure 5c) in the control run is similar to that in the observations with a maximum in boreal autumn-winter, while the variance of Niño3 index is significantly increased in the water hosing experiment in comparison with the 
control run from December to July (figure 5e).

No significant changes are found in the phase-locking of ENSO although the power spectrum from a Multi Tapper Method (Thomson, 1982, this method allows more degrees of freedom and therefore more significance) shows some differences (Figure 5g), be characterized by enhanced peak over 3-3.5 years and reduced power at longer time scales. These changes are in agreement with other models hosed experiments in the frequency band of 2-4 years. DS07 argued that background state changes and in particular the westerlies over the west-central Pacific due to weakened AMOC leads to an eastward shift of the climatological zonal stress and therefore an eastward extension of the warm pool and precipitation (from August to February). This leads to an eastward shift of the zonal wind anomalies associated with El Niño events and increased variance through an enhanced atmospheric response to SST anomalies that is enhanced by the warmer mean SSTs. They have also highlighted the shallow thermocline in the western Pacific from October to February which leads to a reduced thermocline tilt and the enhancement of thermocline feedbacks.

As the variability of ENSO is enhanced due to weakened AMOC, it is expected that this enhancement of ENSO variability might lead to changes in its teleconnection. In the control run, the impacts of the ENSO events are considerable important over the tropical Atlantic, especially the warming (cooling) extension associated with the Niño (Niña) over the Amazon basin and the western tropical Atlantic. As we see in the next section, the interaction between basins will be important to explain the changes in the equatorial Atlantic interannual variability.

\subsubsection{Changes in Tropical Atlantic Interannual variability}

The HadCM3 model simulates the seasonal cycle of the Atl3 index with a warm bias in the annual mean SST of about $\sim 2 \mathrm{C}$ and this warm bias is more pronounced in the summer season (figure $1 \mathrm{~b}$ and figure $5 \mathrm{~b}$ ). Besides, the timing of the cold tongue season is delayed by one month with respect to the observations (JASO vs JJAS figure 5b) and the cooling rate from March to August is remarkably slower in the control run compared with the observations.

Regarding the seasonality of the At13 index variance (figure 5d), the maximum variability over the Atl3 index is found in the season SOND which is delayed by one season with respect to the observations. The Atlantic Niño mode is observed to be more prominent in boreal summer time when the upwelling cold water over the Gulf of Guinea occurs (Zebiak, 1993) together with the seasonal ITCZ-shift (Okumura and Xie, 2004; Xie and Carton, 2004; Polo et al., 2008). Interestingly, the control run shows a minimum of variability in boreal summer, which can be related to the maximum warm bias in that season (figure $5 \mathrm{~b}$ and $5 \mathrm{~d}$ ). The equatorial SST bias peaks during JJA, as a result of the failure to develop the cold tongue (Richter and Xie, 2008). In turn, the equatorial upwelling in this season is the main process bringing interannual variability to the equatorial Atlantic.

Concerning the development of the Atlantic Niño mode in the observations, it starts in boreal spring over the Angola/Benguela region, followed by the eastern equatorial Atlantic in summer and it is driven, in part, by Bjerknes feedback (Keenlyside and Latif, 2007; Polo et al., 2008; Lübbecke et al., 2010). For the HadCM3 control run, the leading mode of SST interannual variability over the Tropical Atlantic from Empirical Orthogonal Function analysis is the so-called Atlantic Niño. This leading mode of TAV in the control explains $20 \%$ of the variance and it can be defined with the Atl3 index (with 0.8 correlation score). In the control run, the Atlantic Niño starts alongshore the 
eastern African coast in early summer and reaches the equator one season later related to anomalous equatorial zonal winds (Figure 2). SST anomalies over the eastern equator develop through Bjerknes feedback. The development of the Atlantic Niño in the control run shows differences between the two phases: from composite maps, the positive phase or Atlantic Niño develops together with a positive ENSO event which peaks the following winter whilst the negative phase or Atlantic Niña is related with the demise of a positive ENSO event from the previous winter (not shown). Despite these differences in relation to ENSO, the Atlantic Niños (Niñas) are preceded by anomalous positive (negative) OHC and decreased (increased) wind stress over the eastern part of the basin and it is associated with more (less) rainfall and surface wind convergence (divergence) over the equator in boreal autumn to winter.

For the AMOC weakening experiment, the annual cycle of the Atl3 index (figure 5b) appears to be similar to that in the control simulation, although the cold tongue season is developed early in JJAS in comparison with the control. The most striking result for the changes in the tropical Atlantic interannual variability is illustrated in figure 5f. The changes are characterized by an increase (up to double) in variance from May to July and a reduction of variance (less than a half) in September-December season in comparison with the control run. These changes in variance of Atl3 in the AMOC weakening experiments relative to the control experiments are statistically significant at $99 \%$ confidence level using F-test.

Additionally, the At13 index power spectrum shows a significant enhancement in the 3-5 years band with respect to the control (figure 5h). The power spectrum for different seasons shows that the two most important peaks are 3.5 years and 4 years in spring, whilst there are no such important peaks in the control run. In autumn, the peaks in the Atl3 index power spectrum are around 4.5- 5.5 years and they also present in the control run (not shown). Thus, significant spectral coherence between At13 and Niño3 indexes is found in [3-5] years band (not shown). The next subsection is dedicated to explain the consequences of this coherent behaviour of the tropical Pacific and Atlantic indexes.

\subsection{2a) Enhancement of the Atlantic-Pacific connection}

The coherent enhancement of the power spectrum for both Niño3 and Atl3 indexes in the [3-5] years band in the AMOC weakening experiment with respect to the control run (figure $5 \mathrm{~g}, \mathrm{~h}$ ) suggests that the two phenomena might be closely related in the water hosing experiment, and this relationship is frequency-locked.

In order to confirm the change in the Atlantic-Pacific interannual variability connection in the perturbation experiment, figure 6 shows the 20-year running correlation between the At13 in JJAS with Niño3 leading and lagging in 4 month-seasons for the control run (figure 6a) and the water hosing experiment (figure 6b). The correlation in the control simulation is not stationary and shows decadal variation. In contrast to what shown in the control experiment, the correlation is enhanced and stationary in the water hosing experiment. Maximum positive correlation is found when Niño3 is leading Atl3 index by one season. This adds an evidence of a stronger inter-tropical basin connection under a weakening of the AMOC with respect to the control run.

The Atlantic-Pacific relationship is frequency-locked in [3-5] years band, this is demonstrated with the significant spectral coherence between indexes (not shown) as well as in the half a period of 20 months in the occurrence in the correlation maps (in figure 6 maximum positive correlation at lag -4 and maximum negative correlation at lag +14 
which makes half a period of 18 months).

\subsection{2b) Processes responsible for the increase of variance at boreal spring season}

It has been shown in previous sections that one of the most important changes in the tropical Atlantic interannual variability due to weakening AMOC is the enhancement of Atl3 variance in late spring and early summer (figure 5f). In this section, we focus on understanding the physical processes involved.

Figure 7 shows the scatter plots of the Niño3 SST in DJF versus heat fluxes over the Atl3 region for different seasons, DJF and MAM, and for the control and perturbation experiments (figure 7a-c). In addition, the heat fluxes anomalies are plotted against the SST anomalies over the At13 region in MJJ (figure 7d-f).

The positive (negative) SST anomalies over the Niño3 in DJF are related to an increase (decrease) of the heat fluxes over Atl3 region from DJF to MAM with significant correlation in the water hosing experiment (figure 7a-c). The increased ENSO impact on the Atl3 region in the water hosing experiment in comparison to the control run is explained by both a larger number of extreme events, and a higher linear regression slope in the relationship in the water hosing experiment. This is demonstrated by sensitivity test when linear regression is plotted omitting the extreme events (SST Niño3 anomaly in DJF>2C), then the correlation increases between SST Niño3 DJF and heat fluxes over the Atl3 for the control run, however, it is still not significant and it is smaller than the correlation for the water hosing experiment (0.11 versus 0.29 ). This suggests that the increased amplitude of ENSO and the change in the background state in the water hosing experiment are the twofold cause of the increased ENSO impact on the heat fluxes at the equatorial Atlantic.

The increase (decrease) of surface heat fluxes in MAM leads to an increase (decrease) of SST anomaly over the equatorial Atlantic in the water hosing experiment in MJJ (figure 7d-f), the heat fluxes anomalies in MAM represent $27 \%$ of the SST anomalies over the equatorial Atlantic in spring (explained variance from linear regression with $\mathrm{r}=0.52$ in figure 7e). However, in the control run, the relationship is not significant (see also Table 1). This indicates that the change of anomalous surface heat flux from winter to spring associated with ENSO plays a key role in enhancing At13 variance in later spring and early summer in the water hosing experiment. In order to illustrate the spatial pattern related to this mechanism, figure 8-9 shows the regression maps of SST, heat fluxes, precipitation and wind speed onto Niño3 index from winter to spring for the control and the experiment runs.

From Niño3 regression maps in the control run (figure 8), the positive (negative) ENSO phase is associated with a maximum warming (cooling) over the central eastern equatorial Pacific in DJF season. This tropospheric anomalies are extended over the whole tropical belt in DJF and the following season, warming (cooling) the surface over the Indian Ocean-western Pacific, the Amazon basin and the western Tropical Atlantic. This widespread tropospheric warming from DJF to MAM (figure 8a and e) is a common feature of ENSO in coupled models and in particular in HadCM3 (Collins et al., 2001). To notice that, from composite maps, the response is stronger for the positive phase of ENSO than for the negative one, pointing to the non-linearities (see discussion in DS07), for the sake of simplicity, this work has focused in the linear part of the response to the ENSO.

In the control run, El Niño (La Niña) in DJF is associated with positive (negative) anomalous heat fluxes over the 
North tropical Atlantic and over the Amazon basin, and opposite sign over the south tropical Atlantic (figure 8b). Changes over the Amazon basin are associated with anomalous negative (positive) precipitation over the Amazon basin and the western equatorial Atlantic (figure 8c) and therefore to the cloud cover anomalies. However, the positive (negative) heat fluxes anomalies over the North Tropical Atlantic are associated with a reduced (increased) wind speed over the area (figure 8d). This ENSO impact SST over the North subtropical Atlantic throughout anomalous subsidence and associated latent heat fluxes has been already observed (Saravanan and Chang, 2000). Besides, from composite maps of streamfunction at 200hPa, ENSO impacts are associated with Barotropic Rossby wave trains to the extratropical Southern Ocean reaching the Atlantic in SON and to the North Atlantic in DJF (not shown).

In MAM (+1), the ENSO impact on the SST is slightly larger than in winter over the equatorial Atlantic (figure 8e) with a wind speed associated pattern: an increased wind speed appears over the equatorial Atlantic and eastern African coast in spring and reduced wind speed occurs over western and central tropical Atlantic (figure 8h). These positive wind speed anomalies are enhanced throughout the next JJA and SON seasons, developing Atlantic Niñalike pattern through Bjerknes feedback (not shown). Thus, in the control run, the SST anomaly of 1C over the Niño3 area in DJF is associated with an increase of $0.2 \mathrm{C}$ over the equatorial Atlantic in MAM (+1) and a decrease of $0.4 \mathrm{C}$ over the equatorial Atlantic afterwards in $\mathrm{SON}(+1$, not shown).

For the water hosing experiment (Figure 9), the regression of DJF Niño3 index shows the increase of anomalous SST over the equatorial Pacific and the warming over the whole tropical belt in MAM (+1, figure 9a,e). Pacific El Niño (La Niña) in the water hosing experiment is associated with a positive (negative) heat fluxes over the equatorial Atlantic. In DJF (figure 9a-c), the increase of heat fluxes are associated with an increase of radiative fluxes by decreasing the precipitation, and therefore, changes in the cloud cover. In MAM (figure 9e-h) the heat fluxes show an increase of 4-8 W/m2 over the equator and especially over the eastern equator (figure $9 \mathrm{~b}, \mathrm{f}$ ). This increase of heat fluxes over the eastern equatorial Atlantic is associated with anomalous zonal wind speed and thus with the windinduced turbulent heat fluxes. The warming of $\sim 0.6 \mathrm{C}$ over the equatorial Atlantic occurs in MJJ, when the mixed layer has integrated the anomalous heat fluxes ENSO-induced from DJF to MAM.

The components of the heat fluxes from DJF to MAM over the eastern equatorial Atlantic due to El Niño in DJF are shown in figure 10. In the control run, only turbulent heat fluxes associated with Niño3 contributes to warm the surface over the equatorial Atlantic. In the water hosing experiment, the latent heat fluxes and shortwave radiation are increased by more than double with respect to the control run. The turbulent heat fluxes are the major component, in particular latent heat fluxes which explain $70 \%$ of the total heat fluxes while short wave radiation explains $30 \%$. Long wave radiation is damping the SST anomalies. Therefore, the anomalous SST over the equatorial Atlantic associated with the total fluxes from DJF to MAM is explained by both: an increase of short wave radiation in DJF by reduced cloud cover, and a decrease of upward latent heat fluxes in MAM due to wind speed reduction.

In summary this increase of At13 variance in spring due to weakened AMO is related to increased variance of surface heat fluxes in response to increase ENSO variance. 1 degree of El Niño3 anomalies contribute to 10W/m2 of total heat fluxes over the Atl3 region from winter to spring, which is translated to above $0.15 \mathrm{C}$ change in three months in an ocean mixed layer of $50 \mathrm{~m}$ over the $\sim 0.4 \mathrm{C}$ SST anomalies. 
In this section the processes associated with the decrease of the Atl3 variance in boreal autumn are explained. In addition to the air-sea exchange of heat, there are heat fluxes associated with vertical advection in the ocean, which are tightly related to changes in the thermocline. The decrease of variance at boreal autumn is associated with a deeper thermocline (figure 4g). We further investigate that by plotting these feedbacks over the equatorial Atlantic in boreal autumn for both, control run and water hosing experiment (Figure 11).

Figure 11a shows the scatter plot of zonal wind stress anomalies over the western equatorial Atlantic (Atl4 region) versus the SST anomalies over the eastern equatorial Atlantic (At13 region). In the control run the anomalous zonal wind in the west equator is explaining more than $60 \%$ of the variability of the SST over the Atl3 region (see Table 1), while in the water hosing experiment this relationship does not hold (Figure 11a), indicating a weak influence of wind stress on equatorial SST anomalies and therefore a weakening local air-sea interaction.

Figure $11 \mathrm{~b}$ shows the scatter plot between the zonal wind stress anomalies over the western equatorial Atlantic and the $\mathrm{OHC}$ anomalies over the Atl3 region. The positive and significant linear regression slopes and correlations (Table 1) in both simulations suggest that the wind stress is able to alter the thermocline over the eastern equatorial basin in the control and water hosing experiments. However, the relationship between wind stress and $\mathrm{OHC}$ is reduced in the water hosing experiment compared with the control run, showing a weakening influence of wind stress anomalies on OHC.

Finally, figure 11c describes the relationship between the OHC and SST anomalies over the Atl3 region. In the control run, the changes in the thermocline are corresponding to changes in SST; however in the water experiment the movements of the thermocline are not able to impact the SST over the region. OHC and SST anomalies are closely related in the control simulation while they are decoupled in the water hosing experiment. The mean thermocline is substantially deepened especially in the cold season (SOND figure 5d). A deeper mean thermocline does not allow thermocline changes to affect the SST. Therefore, the elimination of the Bjerknes feedback by a deeper thermocline is the main cause of the reduced variability of the Atl3 index in autumn season.

This result is in agreement with Haarsma et al. (2008). They have found from their water hosing experiment how a deeper thermocline over the equatorial Atlantic decreases stratification which decreases the entraintment over the eastern equatorial Atlantic by the mean vertical velocity. Therefore a reduction of the Bjerknes feedback was also identified.

In summary, different mechanisms have been found to be behind the two significant changes in Atl3 index variability (figure 5f): On the one hand, the increase of variance in May-July is likely to be a response to the increase of Niño3 variance and its impact onto the equatorial Atlantic. On the other hand, the decrease of variance in SeptemberDecember is a consequence of the deepening of the equatorial thermocline, reducing Bjerknes feedback. 


\section{Discussion}

The model results reported in this article can be summarised as follows. A weakening of the AMOC causes a change in the background state including a strong cooling of the North Atlantic. The changes in the basic state also impact the tropical Pacific, increasing ENSO variability (DS07). Interannual variability in the Tropical Atlantic exhibits two important changes: 1) an increase of variance in boreal spring, which is a remote response to the increase in ENSO variance; and 2) a decrease of variance in boreal autumn, which is caused by a deepening of the thermocline (in response to the weakening of the AMOC) which makes inactive the Bjerknes feedback over the equatorial Atlantic.

Our conclusions regarding the mechanisms responsible for the changes in interannual variability in the tropical Atlantic are consistent with the results from another experiment performed with the same model (Dong and Sutton, 2002b) in which, the SST over the Indo-Pacific basin was relaxed to the model climatology, with active coupling elsewhere. In such simulations, the interannual variability over the tropical Pacific is removed, and accordingly, the variability over the Tropical Atlantic decreases in all seasons as the mean state of the tropical Atlantic thermocline remains the same (not shown).

An important question is to what extent our model results may be relevant to understanding the behavior of tropical Atlantic interannual variability in the real world. It is important to acknowledge immediately that we should not expect too much. First, there is no analogue in the instrumental record for a shut down of the MOC such as that we have examined in the model simulations. Secondly, we recognize that, in common with other climate models, the model we have used suffers from significant biases in the tropical Atlantic region.

Although there is no evidence for a shutdown of the MOC in recent times, there is evidence that variability in the AMO may be partly related to the MOC (with a slow down in the MOC related to a negative phase of the AMO). Therefore, we examine the changes in equatorial variability (Niño3 and Atl3) for different AMO phases (positive AMO period 1921-1959 and negative AMO period 1960-1994), using the HadISST dataset. The ratio of the SST index variance for the negative and positive AMO phases shows: i) an increase of Niño3 variance in all seasons, with significant increases in SON and DJF (figure 12a), consistent with DS07; ii) a significant increase of Atl3 variance in SON (figure 12b); iii) no significant change in Atl3 variance in MAM (figure 12b). There is clearly no simple correspondence between these findings and our model results. The increase in ENSO variance associated with the negative phase of the AMO may well be a factor in the increased variance of Atl3, but the seasonality of this signal differs from that we found in the model. In addition, these observations do not suggest, in any season, a significant decrease in At13 variance associated with the negative phase of the AMO.

There are two possible reasons for the differences between the observed behaviour of Atl3 related to the AMO and our model results. First, the response of tropical Atlantic interannual variability to changes in the MOC could be nonlinear. For example, it is very likely that a deepening of the equatorial thermocline in response to a slow down in the MOC would affect (damp) the role of the Bjerknes feedback in Atl3 variability, but it is plausible that a significant influence only arises for relatively large changes in the MOC, perhaps larger than those that have occurred in the recent past. In this situation, we would expect that changes in ENSO variance might be the dominant influence, as is possibly suggested by Figure 12 for SON in particular. Since both ENSO and Atl3 variance increase in SON for a negative AMO phase, the impact of ENSO onto the equatorial Atlantic could perhaps be the cause of 
the increase in Atl3 variance. The second reason is that biases in our model may be modifying the mechanisms including their seasonal variation - compared to the real world. In spite of these differences, we argue that the two basic mechanisms we have identified: 1) a remote response to changes in ENSO, 2) a response to a deepening of the equatorial thermocline are likely to be sufficiently robust that they do have relevance to understanding the behaviour of tropical Atlantic variability in the real world, even if the application of these ideas requires allowance for the impact model biases. These mechanisms may also be relevant to understanding the observed multidecadal modulation of the correlation between tropical Pacific and tropical Atlantic interannual variability (Polo et al., 2008; Rodriguez-Fonseca et al., 2009; Martin-Rey et al., 2012; Polo et al., 2013). Further understanding the role of these mechanisms in the real world is an important area for future work. 


\section{Summary}

In this study we have investigated the impact of a substantial weakening of the AMOC on interannual variability in the tropical Atlantic region. The main findings are summarised here:

- The AMOC weakening leads to a major change in the annual background state from the deep ocean circulation to the upper atmosphere levels motions (figure 3): an Atlantic SST dipolar pattern occurs together with a southward ITCZ-shift and an increase of surface westerlies driving an anomalous Walker circulation in the equatorial Atlantic. Two cyclonic circulation anomalies straddling at the equator at upper levels appear as a Gill-type response west of the reduced convection in the tropical North Atlantic. In the Pacific, the Walker circulation is modified with an eastward extension of the warm pool and reduced convection over the Atlantic warm pool.

- The equatorial Atlantic seasonal cycle is modified. There is an increase of the already reversed west-east thermocline tilt with respect to the observations and the cold season is shifted earlier by two months together with the anomalously dry-ITCZ shifting northward from MAM to SON and anomalous westerly winds over the central basin (figure 4).

- There are significant changes in tropical interannual variability which can be characterized by the Niño3 and Atl3 indexes for tropical Pacific and Atlantic respectively (figure 5). i) Niño3 index annual cycle is substantially reduced while interannual variability is enhanced throughout the year, especially in winter and spring when it is double that in the control. ii) Atl3 index interannual variability is significantly enhanced in spring (MJJ) up to more than double and reduced in autumn (SOND) by less than half in comparison with the control. iii) The variance in the 3-5 year frequency band is enhanced, versus a reduction in lower frequency variance for both, Atl3 and Niño3 indexes.

- $\quad$ The connection between Atlantic and Pacific tropical basins, as illustrated by the correlation between Niño3 and Atl3 indexes, is enhanced. In the water hosing experiment, Niño3 leads Atl3 by one season in spring and summer, and explains $\sim 60 \%$ of Atl3 variance. The connection is frequency-locked to the 3-4 year periodicity band (figure 6).

- $\quad$ The increase of the Atl3 variability in spring is explained by a larger ENSO impact on the equatorial Atlantic. The increase of variance of the ENSO teleconnects with the equatorial Atlantic in the following spring. For a Niño (Niña) event, there is a reduction (increase) of the wind speed over the equatorial Atlantic and therefore reduced (enhanced) latent heat fluxes from the ocean. Anomalous positive (negative) radiative fluxes to the ocean by changes in the cloud cover also contribute to the changes in SST (figure 7-10).

- $\quad$ The reduction of the Atl3 variability in autumn season is explained by a reduction of the Bjerknes feedback over the equatorial Atlantic. The thermocline deepens in the equatorial Atlantic, decreasing stratification. In the east, although there is variability of the thermocline, the decrease of the stratification does not allow vertical movements to have an impact onto the SST in autumn (figure 11). 
As discussed in Section 4, the comparison between the model results and observations is not straightforward owing to the influence of model biases and the lack of a major MOC weakening event in the instrumental record. However, in our opinion the basic physical mechanisms found in the model simulations are likely to be robust, and therefore have relevance to understanding tropical Atlantic variability in the real world, perhaps with modified seasonality. The extent to which this is true, and whether there are also other mechanisms that could modulate interannual variability in the tropical Atlantic is an important topic for future work. 


\section{Figure Captions}

Figure 1 SST equatorial Atlantic seasonal cycle: a) Seasonal cycle of the climatological SST over the equatorial Atlantic (shaded in C) and the seasonal cycle with the annual mean removed (contour in C) for the observed HadISST dataset for the 1870-2011 period. b) Bias of the HadCM3 model for 200 years of the control run along the equatorial Atlantic, control minus the observations (shaded in C) and the seasonal cycle without the annual mean (contour in $\mathrm{C}$ ).

Figure 2 Atlantic Niño composites in the control run: a) SST composites maps in FMA (left panel) and ASO (right panel) based on the Atl3 index [20W-0E; 3N-3S] score above 1std in ASO (in C). b) Same as a) but for the wind stress (vectors in $\mathrm{N} / \mathrm{m} 2$ ) and the precipitation (shaded in $\mathrm{mm} /$ day). c) Same as a) but for the heat content of the upper ocean 200m (in C). From d) to f) same as a) - c) but for the Atl3 index below -1 std.

Figure 3 Change in the background: Difference of the annual mean between Water hosing experiment and the control run of the variables: a) velocity potential (shaded in $10^{-6} \mathrm{~m}^{2} / \mathrm{s}$ positive for divergence) and streamfunction (contour in $10^{-6} \mathrm{~m}^{2} / \mathrm{s}^{2}$ ) at $200 \mathrm{hPa}$. b) Precipitation (shaded in $\mathrm{mm} /$ day) and wind stress (vectors in $\mathrm{N} / \mathrm{m}^{2}$ ) c) SST (in C) d) Ocean heat content of the upper ocean $200 \mathrm{~m}$ (in C) e) the Meridional overturning circulation (shaded in $\mathrm{Sv}=1 \mathrm{e}+6 \mathrm{~m}^{3} / \mathrm{s}$, contours are referred to as the stream function for the water hosing experiment). Only significant areas from a t-test at $99 \%$ confidence level have been plotted. The differences are performed for 160 years between the water hosing experiment after the adjustment period and the control run.

Figure 4 Change in the equatorial seasonal cycle: a)-c) seasonal cycle of the equatorial band [3N-3S] for the control run for $\mathrm{OCH} 200 \mathrm{~m}\left({ }^{\circ} \mathrm{C}\right.$, left) SST (central) and precipitation $\left(\mathrm{mm} \mathrm{day}^{-1}\right)$ and wind stress $\left(\mathrm{N} \mathrm{m}^{-2}\right.$, right). For the OHC and the SST, the superimposed contours are the seasonal cycle with the annual mean removed. d)-f) Differences between water hosing experiment and the control run for the variables OHC (left) SST(central) and the precipitation (shaded right) and the zonal wind stress (contour right). For d)-f) the significance has been tested with a t-test of equal means at $95 \%$ confidence level.

Figure 5 Seasonal cycle of the indexes: a) -b) Seasonal cycle mean c)-d) standard deviation $\left({ }^{\circ} \mathrm{C}\right)$, for the Niño3 ([150W-90W; 5N-5S], left) and Atl3 ([20W-0E; 3N-3S], right) index for the observations, the control run and the water hosing experiment. e)-f) Ratio variance between water hosing experiment and control run for the indexes (dark blue) and the confidence interval for a F-test with 90\% (light blue-dashed) 99\% (light blue-solid) of confidence level. The interval containing the unit has $\mathrm{p}=0.01$ of the variance being not equal. $\mathrm{g}$ )- $\mathrm{h}$ ) Power spectrum for the annual mean of the two indexes for the control run and the water hosing experiment performed from the Multi-Tapper Method. Shaded areas corresponds to the confidence interval at 95\% confidence level of the spectrum of AR(1) process with characteristics of the time series.

Figure 6 Atl3-Niño3 correlation: a) 20-year running correlation between summer Atl3 ([20W-0E; 3N-3S], JJA 4months season) and lagged Niño3 [150W-90W; 5N-5S]. X-axis corresponds to the different lags for Niño3 (months), $\mathrm{x}$-axis corresponds to the 200 years of the control simulation; each year is the beginning of the 20 year periods. Only significant areas from a t-test at $90 \%$ confidence level have been plotted for effective number of degrees of freedom. b) Same as a) but for the water hosing experiment. 
Figure 7 Mechanism for spring: Scatter plots of:

a)-c): Total heat flux anomalies over the region Atl3 [20W-0E; 3N-3S] versus SST anomalies over Niño3 region [150W-90W; 5N-5S] in winter DJF (a), Total heat flux anomalies over Atl3 in spring MAM versus SST anomalies over Niño3 in winter DJF (b), Total heat flux anomalies over the Atl3 integrated from winter to spring versus SST anomalies over Niño3 in winter DJF (c).

d)-f): SST anomalies over Atl3 region in spring MJJ versus total heat flux anomalies over At13 region the previous winter (d) SST anomalies over At13 region in spring MJJ versus total heat flux anomalies over Atl3 region the simultaneous spring (e), SST anomalies over Atl3 region in spring MJJ versus total heat flux anomalies over Atl3 region integrated from winter to the following spring (f).

For the control (diamonds) and the water hosing experiment (bold circles) and linear regressions have been plotted in red. The heat fluxes are in $\mathrm{W} / \mathrm{m} 2$ and defined positive downward and SST are in C.

Figure 8 Regression Niño3 DJF Ctrl: Regression of SST in C (a,e) Total Heat Fluxes in W/m2 positive downward (b,f) precipitation in $\mathrm{mm} /$ day and wind stress in N/m2 $(\mathrm{c}, \mathrm{g})$ and wind stress speed in N/m2 (d,h) onto Niño3 DJF index non-standardized simultaneously (top) and the following spring (bottom) for the control run.

Figure 9 Regression Niño3 DJF Wat: Same as 8 but for the water hosing experiment run.

Figure 10 Regression of anomalous Heat Fluxes: Regression of anomalous heat fluxes components (in W/m2 positive downward) onto Niño3 Index DJF, integrated in time from winter to the following spring and averaged over Atl3 index region for the control (diamonds) and the water hosing experiment (bold circles). Regression of anomalous SST (in C) changes from DJF to MAM onto Niño3 index DJF is shown in red in the right side x-axis.

Figure 11 Mechanism for autumn: SST anomalies over the Atl3 region [20w-0E; 3N-3S] versus zonal wind stress over the region At14 [50W-20W; 5N-5S] for the season SOND (a), OHC anomalies over Atl3 region [20w-0E; 3N$3 \mathrm{~S}$ ] versus zonal wind stress over the region At14 [50W-20W; 5N-5S] for the season SOND (b), OHC versus SST anomalies over At13 region [20w-0E; 3N-3S] for SOND (c). For the control (diamonds) and the water hosing experiment (bold circles) and only significant linear regressions have been plotted in red. The zonal wind stress is in $\mathrm{N} / \mathrm{m} 2$ and the OHC and SST are in C.

Figure 12 Variability in the observations: a) Ratio between the variance of Niño3 index for negative AMO phase (1960-1994) and the variance for positive AMO phase (1921-1959) for each season (blue line) and the confidence interval for an F-test with $90 \%$ of the confidence level (light-blue). b) Same as a) but for the Atl3 index.

Table 1: Correlation coefficients between the different components related to the mechanisms explained in Figure 7 and Figure 11 for the water hosing experiment and the control run. 
Acknowledgements

Irene Polo has been supported by a postdoctoral fellowship funded by the Spanish Government. This work has been also possible thanks to the Spanish projects: Tropical Atlantic Variability and the Climate Shift (TRACS-CGL2009-10285) and MOVAC. BD and RTS are supported by the U.K. National Centre for Atmospheric Science-Climate (NCAS-Climate) at the University of Reading. We also wish to thank two anonymous reviewers for their constructive comments and suggestions. 


\section{References}

An S. I. (2008) A review on interdecadal changes in the nonlinearity of the El Niño-Southern Oscillation. Theor. Appl. Climatol., 97, 29-40.

Baines, P. G., and C. K. Folland (2007) Evidence for a Rapid Global Climate Shift across the Late 1960s. J. Clim., 20, 2721-2744.

Balan Sarojini B., J. M. Gregory, R. Tailleux, G. R. Biggs A. T. Blaker, D. Cameron, N. R. Edwards, A. P. Megann, L. C. Shaffrey, and B. Sinha (2011) High frequency variability of the Atlantic meridional overturning circulation. Ocean Sci. Discuss., 8, 219-246, 2011

Bjerknes, J., (1969) Atmospheric teleconnections from equatorial Pacific. Mon. Wea. Rev., 97, 163-172.

Brayshaw D. J., T. Woolings and M. Vellinga (2009) Tropical and Extratropical Responses of the North Atlantic Atmospheric Circulation to a Sustained Weakening of the MOC. J. Climate, 22, 3146-3155.

Breugem, W.-P., W. Hazeleger, and R. J. Haarsma (2006) Multimodel study of tropical Atlantic variability and change, Geophys. Res. Lett., 33, L23706, doi: 10.1029/2006GL027831.

Chang, P., L. Ji and H. Li (1997) A decadal climate variation in the tropical Atlantic ocean from thermodynamic air-sea interactions, Nature, 385, 516-518.

Chang P.., Y. Fang, R. Saravanan, L. Ji and H. Seidel (2006) The cause of the fragile relationship between the Pacific el Niño and the Atlantic Niño. Nature, 443, 324-328.

Chang CY, Carton JA, Grodsky SA, Nigam S (2007) Seasonal climate of the tropical Atlantic sector in the NCAR Community Climate System Model 3: error structure and probable causes of errors. J. Climate, 21: 1053-1070.

Chang, P., R. Zhang, W. Hazeleger, C. Wen, X Wan, K. ji, R. Haarsma, WP Breugem and H. Seidel (2008) Oceanic link between abrupt changes in the North Atlantic ocean and the African monsoon. Nature GeoSciences, 1.

Chen W., B. Dong and R. Lu (2010) Impact of the Atlantic Ocean on the multidecadal fluctuation of El NiñoSouthern Oscillation-South Asian monsoon relationship in a coupled general circulation model. J. Geophys. Res., 115, D17109, doi: 10.1029/2009JD013596.

Chiang J. C. H, Y. Kushnir and S. E. Zebiak (2000) Interdecadal changes in eastern Pacific ITCZ variability and its influence on the Atlantic ITCZ. Geophys. Res. Lett., 27, 3687-3690.

Chiang K, W. Cheng, and C. M. Bitz (2008) Fast teleconnections to the tropical Atlantic sector fromAtlantic thermohaline adjustment.Geophys. Res. Lett., 35, L07704, doi:10.1029/2008GL033292.

Collins M., S. F. B. Tett and C. Cooper (2001) The internal climate variability of HadCM3, a version of the Hadley Centre coupled model without flux adjustments. Clim. Dyn., 17, 61-81.

Collins, W. D., and Coauthors, (2006) The Community Climate System Model Version 3 (CCSM3). J. Climate, 19, 2122-2143. doi: 10.1175/JCLI3761.1.

Cunningham, S. A., et al., (2007) Temporal Variability of the Atlantic Meridional Overturning Circulation at 26.5 N. Science, 317, 935-938, doi:10.1126/science.1141304.

Curry, R., B. Dickson, and I. Yashayaev (2003), A change in the freshwater balance over the Atlantic Ocean over the past four decades, Nature, 426, 826-829.

Dahl, K. A., A. J. Broccoli and R. J. Stouffer (2005) Assessing the role of North Atlantic freshwater forcing in millennial scale climate variability: a tropical Atlantic perspective. Clim. Dyn, 24: 325-346 DOI 10.1007/s00382004-0499-5.

De Almeida, R. A. F. and P. Nobre (2012) On the Atlantic cold tongue mode and the role of the Pacific ENSO. Ocean Sci. Discuss., 9, 163-185, doi: 10.5194/osd-9-163-2012. 
Ding H., N. S. Keenlyside and M. Latif (2011) Impact of the Equatorial Atlantic on the El Niño Southern Oscillation. Clim. Dyn., doi: 10.1007/s00382-011-1097-y.

Dong B. W. and R. T. Sutton (2002a) Adjustment of the coupled ocean-atmosphere system to a sudden change in the Thermocline Circulation. Geophys. Res. Lett., 29, 1728.

Dong B. W. and R. T. Sutton (2002b) Variability in North Atlantic heat content and heat transport in a coupled ocean-atmosphere GCM, Climate Dynamics, 19, 485-497. doi:10.1007/s00382-002-0239-7

Dong, B. and Sutton, R. T. (2005) Mechanism of Interdecadal Thermohaline Circulation Variability in 10 a Coupled Ocean-Atmosphere GCM. J. Climate, 18, 1117-1135.

Dong B. D. R. T. Sutton and A. A. Scaife, (2006) Multidecadal modulation of El Niño-Southern Oscillation (ENSO) variance by Atlantic Ocean sea surface temperatures. Geophys. Res. Lett., 33 Lo8705.

Dong B. W. and R. T. Sutton (2007) Enhancement of ENSO variability by a weakened Atlantic Thermocline Circulation in a Coupled GCM. J. Climate, 20, 4920-4939.

Enfield, D. B. and D. A. Mayer (1997) Tropical Atlantic SST variability and its relation to El Niño-Southern Oscillation. J. Geophys. Res. 102, 929-945.

Fedorov, A, and S. G. Philander (2000) Is El Niño changing? Science, 288, 1997-2002.

Gordon , C., C. Cooper, C. A. Senior, H. Banks, J. M. Gregory, T. C. Johns, J.F. B. Mitchell and R. A. Wood (2000) The simulation of SST, sea ice extents and ocean heat transports in a version of the Hadley Centre coupled model without flux adjustments. Clim. Dyn., 16, 147-168.

Grodsky, S., J. Carton, S. Nigam, and Y. Okumura, (2012) Tropical Atlantic Biases in CCSM4. J. Climate, 25, 3684-3701. doi:10.1175/JCLI-D-11-00315.1.

Guilyardi, E., (2005), El Niño-mean state-seasonal cycle interactions in a multi-model ensemble. Clim. Dyn, 26, 329-348.

Haarsma, R.J., E. Campos, W. Hazeleger, and C. Severijns (2008) Influence of the Meridional Overturning Circulation on Tropical Atlantic Climate and Variability.J. Climate, 21, 1403-1416.

Hazeleger, W., and S. Drijfhout (2006) Subtropical cells and meridional overturning circulation pathways in the tropical Atlantic, J. Geophys. Res., 111, C03013, doi:10.1029/2005JC002942.

Jochum M., and P. Malanotte-Rizzoli (2001) Influence of the Meridional Overturning Circulation on TropicalSubtropical Pathways. J. Phys. Oceanogr., 31, 1313-1323.

Joseph, R., and S. Nigam (2006) ENSO evolution and teleconnections in IPCC's twentieth-century climate simulations: Realistic representation? J. Climate, 19, 4360-4377.

Keenlyside N., and M. Latif (2007) Understanding Equatorial Atlantic Interannual Variability, J. Climate, 20, 131142

Knight J R, R J Allan, C K Folland, M Vellinga and M E Mann (2005) A signature of persistent natural thermohaline circulation cycles in observed climate. Geophys. Res. Lett., 32, L20708, doi: 10.1029/2005GL024233.

Kraus E. B., and J. S. Turner (1967) A one-dimensional model of the seasonal thermocline II. The general theory and its consequences. Tellus, 19, 98-106.

Large, W.G. and G. Danabasoglu (2006) Attribution and Impacts of Upper Ocean Biases in CCSM3. J. Climate, $19,2325-2346$.

Latif, M., and T. P. Barnett (1995) Interaction of the tropical oceans, J. Climate., 8, 952- 964.

Laurian A., S. S. Drijfhout, W. Hazeleger and R. van Dorland (2009) Global surface cooling: The atmospheric fast feedback response to a collapse of the thermohaline circulation. Geophys. Res. Lett., 36, L20708, doi: 10.1029/2009GL040938. 
López-Parages, J., and B. Rodríguez-Fonseca (2012) Multidecadal modulation of El Niño influence on the EuroMediterranean rainfall, Geophys. Res. Lett., 39, L02704, doi:10.1029/2011GL050049.

Lu, R.-Y., and B.-W. Dong (2008) Response of the Asian summer monsoon to a weakening of Atlantic thermohaline circulation. Adv. in Atmos. Sci., 25, 723-736.

Lübbecke, J. F., C. W. Böning, N. S. Keenlyside, and S. P. Xie (2010) On the connection between Benguela and equatorial Atlantic Niños and the role of the South Atlantic Anticyclone, J. Geophys. Res., 115, C09015, doi:10.1029/2009JC005964.

Lübbecke, J. F., and M. J. McPhaden (2012) On the Inconsistent Relationship between Pacific and Atlantic Niños. J. Climate, 25, 4294-4303.

Mantua, N. J. and S. R. Hare (2002) The Pacific Decadal Oscillation, J. Oceanogr., 58, p. 35-44. doi:10.1023/A:1015820616384.

Martín-Rey M., I. Polo, B. Rodríguez-Fonseca and F. Kucharski (2012) Changes in the Interannual Variability of the Tropical Pacific as a response to an equatorial Atlantic forcing. Sci. Mar. Vol. 76, No. S1 ISSN: 0214-8358 (in press).

Mechoso, C. R., and co-authors, 1995: The seasonal cycle over the tropical Pacific in coupled ocean-atmosphere general circulation models, Mon. Weather Rev., 123, 2825-2838.

Miller A J, D R Cayan, T P Barnett, N E Graham and J M Oberhuber (1994) The 1976-77 -Climate Shift of the Pacific Ocean. Oceanogr. 7, 21-26.

Moon, B.-K., S.-W. Yeh, B. Dewitte, J.-G. Jhun, I.-S. Kang, and B. P. Kirtman (2004), Vertical structure variability in the equatorial Pacific before and after the Pacific climate shift of the 1970s, Geophys. Res. Lett., 31, L03203, doi:10.1029/2003GL018829.

Munnich M., and J. D. Neelin (2005) Seasonal influence of ENSO on the Atlantic ITCZ and equatorial South America, Geophys. Res. Lett., 32, L21709, doi:10.1029/2005GL023900.

Neelin J. D., C. Chou and H. Su (2003) Tropical drought regions in global warming and El Niño teleconnections. Geophy. Res. Lett., 30. doi: 10.1029/2003GL018625.

Nobre, P., and J. Shukla (1996) Variations of sea surface temperature, wind stress and rainfall over the tropical Atlantic and South America. J. Climate, 9, 2464-2479

Okumura, Y., and SP Xie (2004) Interaction of the Atlantic Equatorial Cold Tongue and the African Monsoon. $J$. Climate, 17, 3589-3602.

Pacanowsky R.C. And SGH Philander (1981) Parameterization of vertical mixing in numerical models of tropical oceans. J. Phys. Oceanogr., 11, 1443-1451.

Philander S. G. H., (1990) El Niño, La Niña, and the Southern Oscillation. International Geophysics Series, Vol. 46, Academic Press, 293 pp.

Polo I., B. Rodriguez-Fonseca, T. Losada and J. Garcia-Serrano (2008) Tropical Atlantic variability modes (1979-2002). Part I: Time-evolving SST modes related to West African rainfall. J. Climate, 21, 6457-6475. DOI:10.1175/2008JCLI2607.1.

Polo I., M. Martin-Rey, B. Rodriguez-Fonseca, C. R. Mechoso, F. Kucharski (2013) Processes in the Influence of Tropical Atlantic Sea Surface Temperatures on Pacific la Niña Onset (submitted).

Rayner, N. A., D. E. Parker, E. B. Horton, C. K. Folland, L. V. Alexander, D. P. Rowell, E. C. Kent, and A. Kaplan (2003) Global analyses of sea surface temperature, sea ice and night marine air temperature since the late nineteenth century. J. Geophys. Res., 108, 4407, doi:10.1029/2002JD002670.

Richter I., and S. P. Xie (2008) On the origin of equatorial Atlantic biases in coupled general circulation models. 
Clim. Dyn., 31: 587-598. Doi: 10.1007/s00382-008-0364-z.

Richter I., S. K. Behera, Y. Masumoto, B. Taguchi, H. Sasaki and T. Yamagat (2013) Multiple causes of interannual sea surface temperature variability in the equatorial Atlantic Ocean. Nature GeoScience, 6, doi: 10.1038/NGEO1660.

Robson J., R. Sutton, K. Lohmann, D. Smith and M. D. Palmer (2012) Causes of the Rapid Warming of the North Atlantic Ocean in the mid 1990s. J. Climate, 25, 4116-4134. doi: 10.1175/JCLI-D-11-00443.1.

Rodríguez-Fonseca, B., I. Polo, J. García-Serrano, T. Losada, E. Mohino, C. R. Mechoso, and F. Kucharski (2009) Are Atlantic Niños enhancing Pacific ENSO events in recent decades?, Geophys. Res. Lett., 36, L20705, doi:10.1029/2009GL040048.

Rodriguez-Fonseca～B., S. Janicot, E. Mohino, T. Losada, J. Bader, C. Caminade, B. Fontaine, J. Garcia-Serrano, S. Gervois, M. Joly, I. Polo, P. Ruti, P. Roucou and A. Voldoire (2010) Interannual and decadal SST-forced responses of the West African monsoon, Atm Sci. Lett., 12, 1, 67-74. Doi: 10.1002/asl.308

Rodriguez-Fonseca, B., I. Polo, T. Losada, E. Mohino, M. Martin-Rey (2012) The relation between The Atlantic and Pacific Niños in CMIP simulations: A Multidecadal Modulation. Extended Proceeding of World Climate Research Project Open Science Conference (WCRP OSC), Denver, USA.

Saravanan, R., and P. Chang (2000) Interaction between tropical Atlantic variability and El Niño-Southern Oscillation. J. Climate, 13, 2177-2194.

Send, U., M. Lankhorst, and T. Kanzow (2011), Observation of decadal change in the Atlantic meridional overturning circulation using 10 years of continuous transport data. Geophys. Res. Lett., 38, L24606, doi:10.1029/2011GL049801.

Spencer, H., R. Sutton and J. M. Slingo (2007) El Niño in a Coupled Climate Model: Sensitivity to Changes in Mean State Induced by Heat Flux and Wind Stress Corrections. J. Climate, 20, 2273-2298.

Stouffer, R. J., and Coauthors (2006) Investigating the causes of the response of the thermohaline circulation to past and future climate changes. J. Climate, 19, 1365-1387.

Su H., and J. D. Neelin (2002) Teleconnection Mechanisms for Tropical Pacific Descents Anomalies during El Niño. J. Atm. Sci., 59, 2694-2712.

Sutton, R. T. and D. L. R. Hodson (2007), Climate Response to Basin-Scale Warming and Cooling of the North Atlantic Ocean. J. Climate, 20, 891-907.

Tett, S. F. B., T. C. Johns, J. F. B. Mitchell (1997) Global and regional variability in a coupled AOGCM. Clim. Dyn., 13: 303-323.

Timmermann A., S. An, U. Krebs, and H. Goosse, (2005) ENSO suppression due to a weakening of the North Atlantic thermohaline circulation. J. Climate, 18, 3122-3139.

Timmermann A., Y. Okumura, S.-I. An, A. Clement, B. Dong, E. Guilyardi, A. Hu, J. Jungclaus, U. Krebs, M. Renold, T.F. Stocker, R.J. Stouffer, R. Sutton, S.-P. Xie, J. Yin, (2007) The influence of a weakening of the Atlantic meridional overturning circulation on ENSO. J. Climate. 20, 4899-4919.

Tokinaga H., S. P. Xie (2011) Weakening of the equatorial Atlantic cold tongue over the past six decades. Nature. GeoSci. doi:10.1038/NGEO1078.

Tokinaga, J., S. P. Xie, A. Timmermann, S. McGregor, T. Ogata, H. Kubota and Y. M. Okumura (2012) Regional Patterns of Tropical Indo-Pacific Climate Change: Evidence of the Walker Circulation Weakening, J. Climate, 25, 1689-1710.

Thomson D. J., (1982) Spectrum estimation and harmonic analysis. Proc. IEEE, 70 (1982), pp. 1055-1096.

Trenberth, K. E., (1990), Recent observed interdecadal climate changes in the Northern Hemisphere. Bull. Amer. 
Meteor. Soc., 71, 988-993.

van Oldenborgh GJ, te Raa LA, Dijkstra HA, Philip SY (2009) Frequency- or amplitude-dependent effects of the atlantic meridional overturning on the tropical pacific ocean. Ocean Sci 5, 293-301. doi:10.5194/os-5-293-2009.

Vecchi, G. A., B. J. Sonden, A. T. Wittenberg, I.M. Held, A. Leetmaa and M. J. Harrison (2006) Weakening of tropical Pacific atmospheric circulation due to anthropogenic forcing, Nature, 441, 73-76. doi:10.1038/nature04744.

Vellinga, M. and R. A. Wood (2002), Global Climatic Impacts of a Collapse of the Atlantic Thermohaline Circulation, Climatic Change, 54, 251-267.

Wang, C., and D. B. Enfield (2001) The tropical Western Hemisphere warm pool. Geophys. Res. Lett., 28, 1635 1638 .

Wang, B. and S. I. An (2002), A mechanism for decadal changes of ENSO behavior: roles of background wind changes. Clim. Dyn., 18, 475-486.

Wang, C., S. K. Lee and C. R. Mechoso (2010) Interhemispheric Influence of the Atlantic Warm Pool on the Southeastern Pacific, J. Climate,23, 404-418.

Wen, C., P. Chang and R. Saravanan (2010): Effect of Atlantic Meridional Overturning Circulation Changes on Tropical Atlantic Sea Surface Temperature Variability: A 21/2-Layer Reduced-Gravity Ocean Model Study. J. Climate, 23, 312-332.

Willis, J. K., 2010: Can in situ floats and satellite altimeters detect long-term changes in Atlantic Ocean overturning? Geophysical Research Letters, 37, L06602. doi: 10.1029/2010GL042372.

Woollings, T., J. M. Gregory, J. G. Pinto, M. Reyers and D. J. Brayshaw (2012) Response of the North Atlantic storm track to climate change shaped by ocean-atmosphere coupling, Nature Geoscience, 5:313-317.

Wright DK (1997) A new eddy mixing parametrization and ocean general circulation model. Int WOCE Newslett 29: 27-29.

Wu, L., C. Li, C. Yang and S.P. Xie (2008): Global Teleconnections in Response to a Shutdown of the Atlantic Meridional Overturning Circulation. J. Climate, 21, 3002-3019.

Xie, S-P., and J. A. Carton, 2004: Tropical Atlantic variability: Patterns, mechanisms, and impacts. Earth Climate: The Ocean-Atmosphere Interaction, Geophys. Monogr., Amer. Geophys. Union, 121-141.

Xie, S.-P., Miyama, T., Wang, Y., Xu, H., De Szoeke, S. P., Small, R. J. O., Richards, K. J., Mochiziku, T., and Awaji, T (2007): A regional ocean-atmosphere model for eastern Pacific climate: toward reducing tropical biases, J. Climate, 20, 1504-1522.

Zebiak, S. E. (1993) Air-sea Interaction in the Equatorial Atlantic Region J. Climate, 6, 1567-1586.

Zhai, X., and L. Sheldon, 2012: On the North Atlantic ocean heat content change between 1955-1970 and 19801995. J. Climate, 25, 3619-3628. doi:10.1175/JCLI-D-11-00187.1

Zhang, R., and T. L. Delworth (2005) Simulated tropical response to a substantial weakening of the Atlantic thermohaline circulation. J. Climate, 18, 1853-1860 

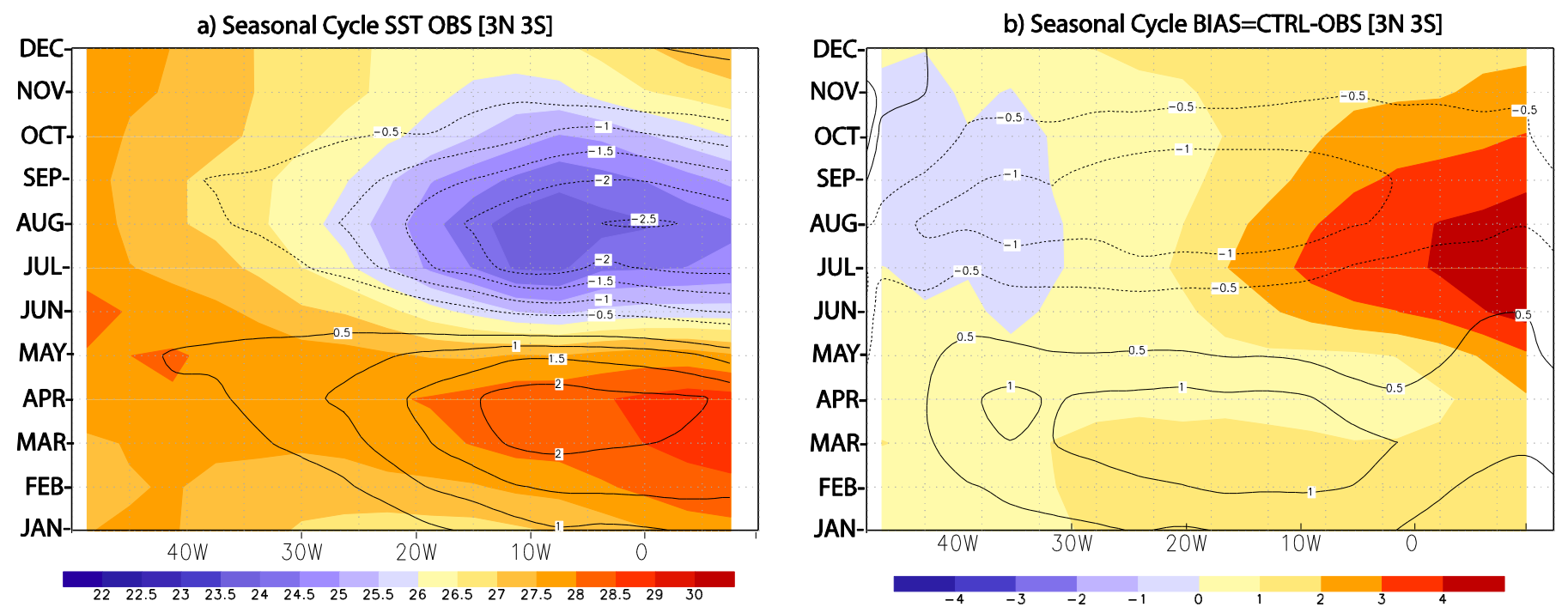

Figure 1 SST equatorial Atlantic seasonal cycle: a) Seasonal cycle of the climatological SST over the equatorial Atlantic (shaded in C) and the seasonal cycle with the annual mean removed (contour in C) for the observed HadISST dataset for the 1870-2011 period. b) Bias of the HadCM3 model for 200 years of the control run along the equatorial Atlantic, control minus the observations (shaded in $\mathrm{C}$ ) and the seasonal cycle without the annual mean (contour in $\mathrm{C}$ ). 
a) SST Atl3 >1 std FMA-ASO
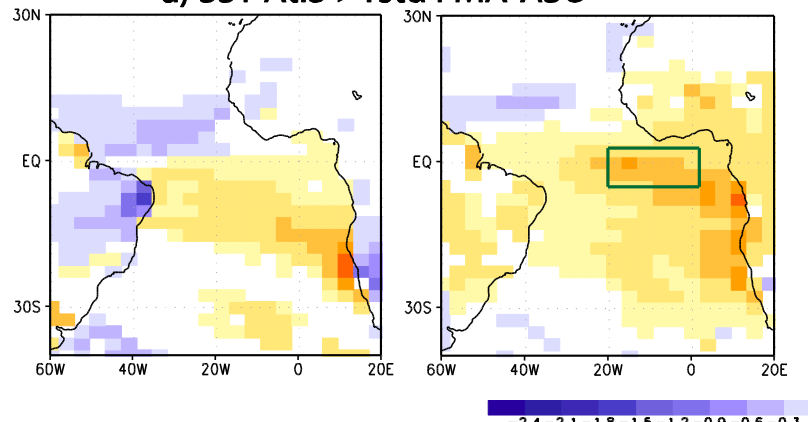

b) Pt wind stress Atl3 > 1std FMA-ASO
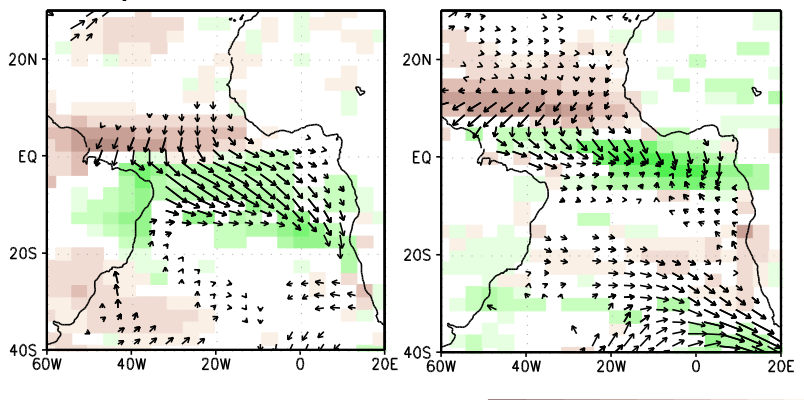

$-1.6-1.4-1.2-1-0.8-0.6-0.4-0.2$

c) OHC Atl3>1std FMA-ASO
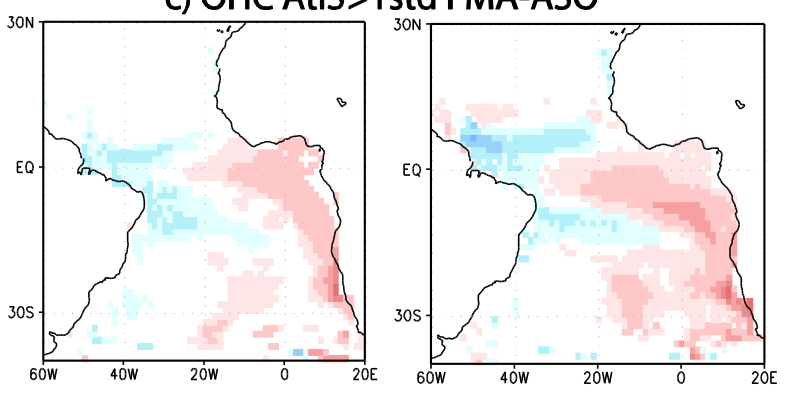

$-1.6-1.4-1.2-1-0.8-0.6-0.4-0.200 .20 .40 .60 .8 \div 1.2 .4 .4 .6$
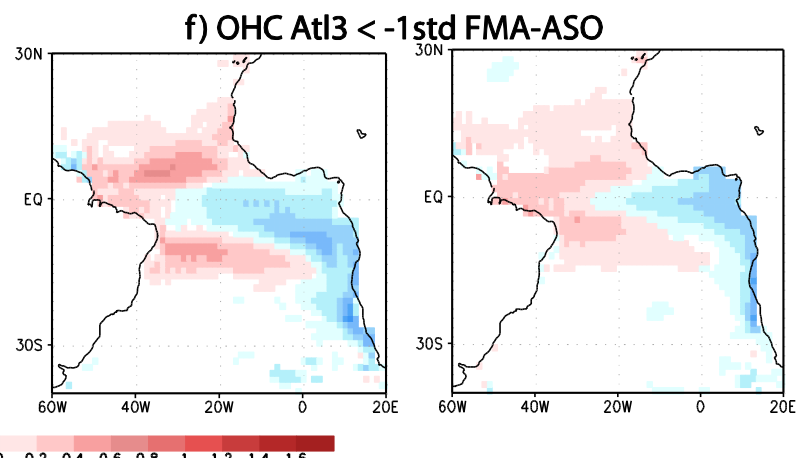

Figure 2 Atlantic Nino composites in the control run: a) SST composites maps in FMA (left panel) and ASO (right panel) based on the Atl3 index score above 1std in ASO (in C). b) Same as a) but for the wind stress (vectors in N/m2) and the precipitation (shaded in $\mathrm{mm} /$ day). c) Same as a) but for the heat content of the upper ocean $200 \mathrm{~m}$ (in C). From d) to f) same as a) - c) but for the Atl3 index below -1std. 
a) Vpot Strf 200hPa WATHos-CTRL

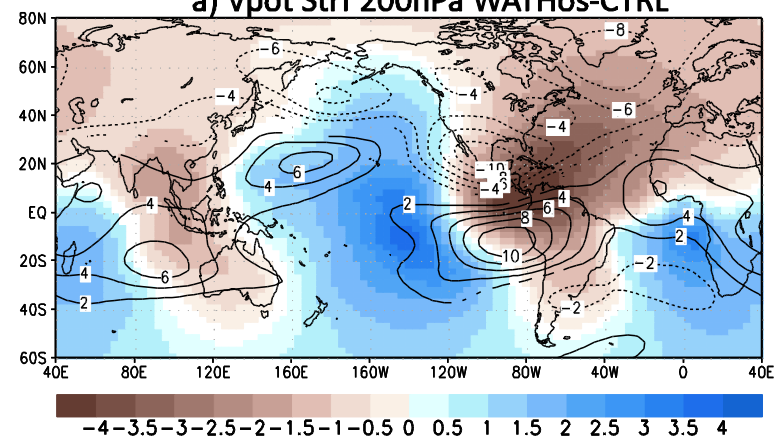

b) Pt Wind Stress WATHos-CTRL

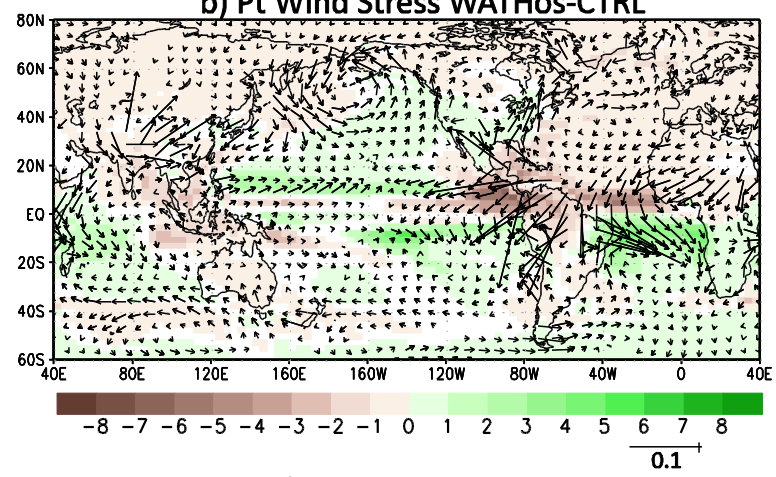

c) SST WATHOS-CTRL

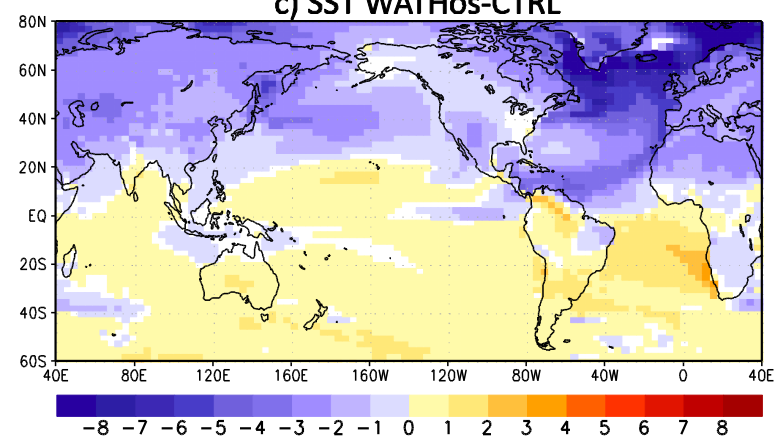

d) OHC $200 \mathrm{~m}$ WATHOS-CTRL

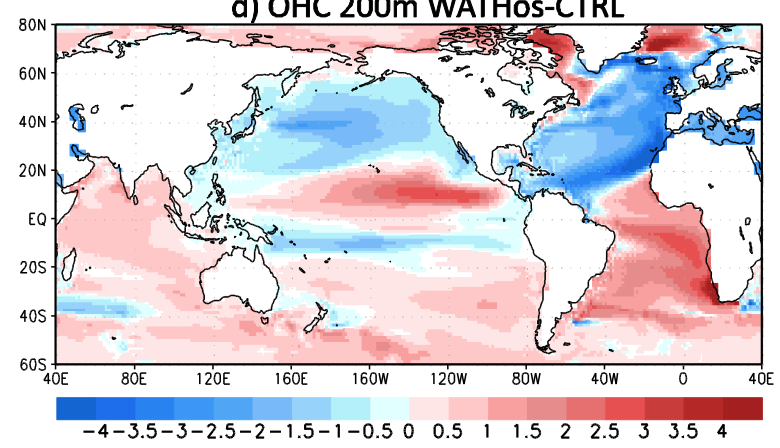

e) MOC WATHos-CTRL

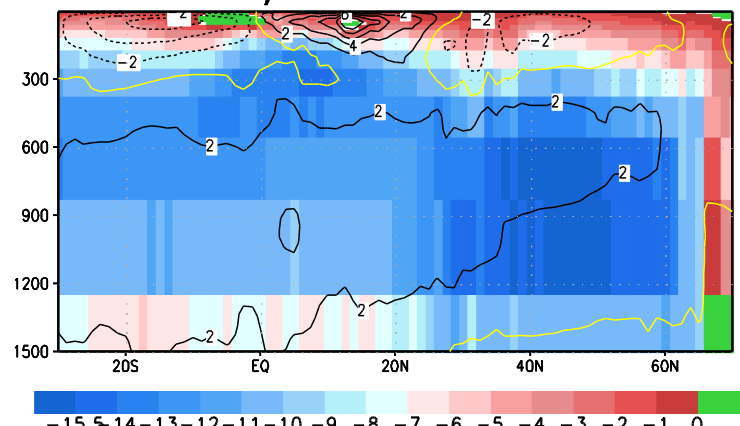

Figure 3 Change in the background: Difference of the annual mean between Water hosing experiment and the control run of the variables: a) velocity potential (shaded in $10^{-6} \mathrm{~m}^{2} / \mathrm{s}$ positive for divergence) and streamfunction $\left(\right.$ contour in $10^{-6} \mathrm{~m}^{2} / \mathrm{s}^{2}$ ) at 200hPa. b) Precipitation (shaded in $\mathrm{mm} /$ day) and wind stress (vectors in N/m ${ }^{2}$ ) c) SST (in C) d) Ocean heat content of the upper ocean $200 \mathrm{~m}$ (in C) e) the Meridional overturning circulation (shaded in $\mathrm{Sv}=1 \mathrm{e}+6 \mathrm{~m}^{3} / \mathrm{s}$, contours are referred to as the stream function for the water hosing experiment). Only significant areas from a t-test at $99 \%$ confidence level have been plotted. The differences are performed for 160 years between the water hosing experiment after the adjustment period and the control run. 
a) $\mathrm{OHC} 200[3 \mathrm{~N} 3 \mathrm{~S}] \mathrm{CTRL}$

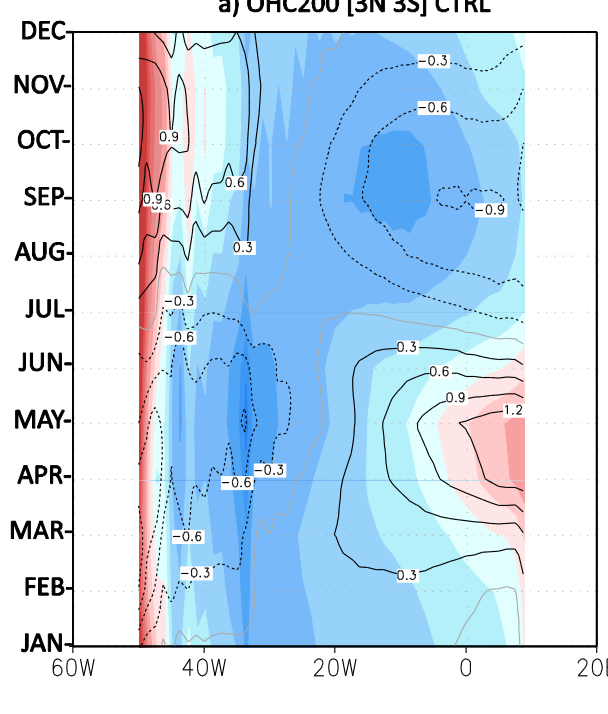

1717.51818 .51919 .52020 .52121 .52222 .52323 .524 d) OHC200 [3N 3S] WATHOS-CTRL

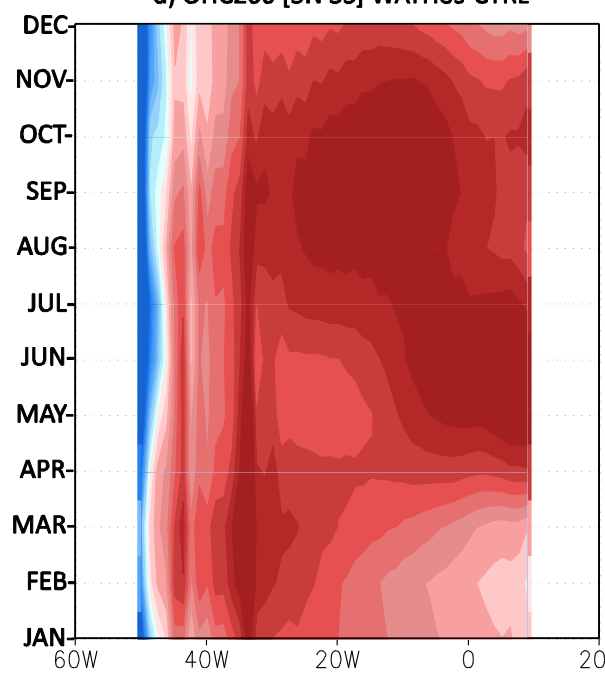

b) SST [3N 3S] CTRL

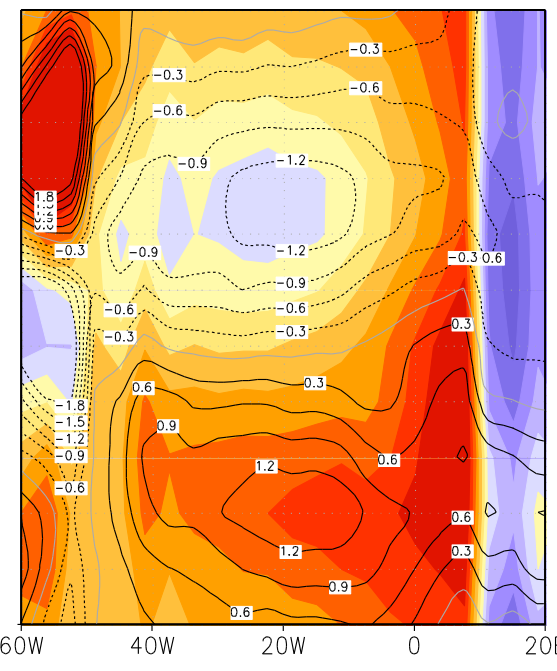

2.52323 .52424 .52525 .52626 .52727 .52828 .52929 .5

e) SST [3N 3S] WATHos-CTRL

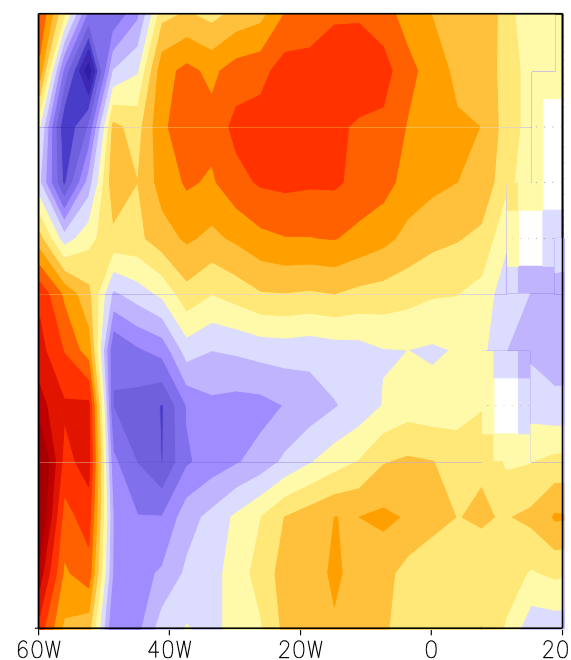

c) PT-Wstr [3N 3S] CTRL

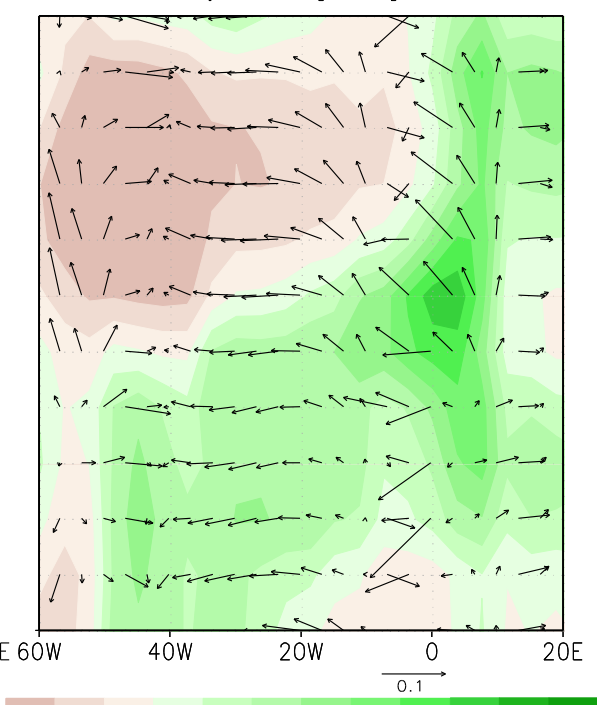

$\begin{array}{lllllllllll}1.5 & 3 & 4.5 & 6 & 7.5 & 9 & 10.5 & 12 & 13.5 & 15 & 16.5\end{array}$

f) PT-Wstr [3N 3S] WATHos-CTRL

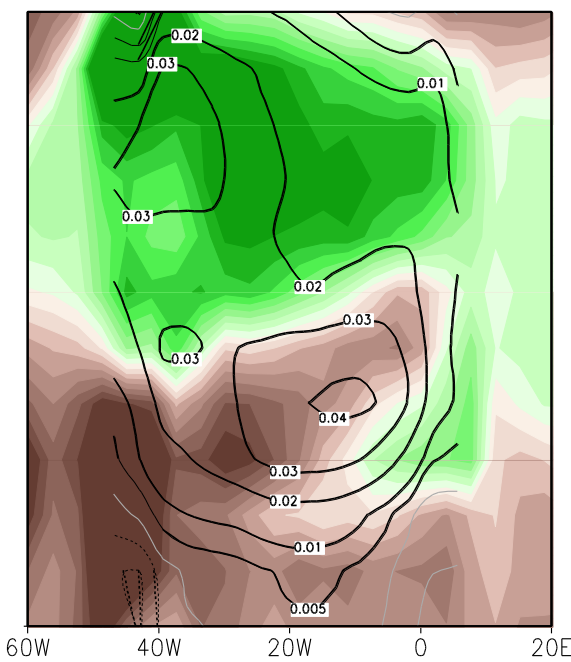

$-1.61 .41 .2-1-0.80 .60 .40 .200 .20 .40 .60 .8 \quad 1 \quad 1.21 .41 .6$

$-2.42 .+1.81 .51 . z 0.90 .60 .300 .30 .60 .91 .21 .51 .82 .12 .4$

-4-3.5-3-2.5-2-1.5-1-0.50 $0.5 \quad 1 \quad 1.5222 .5333 .54$

Figure 4 Change in the equatorial seasonal cycle: a)-c) seasonal cycle of the equatorial band [3N-3S] for the control run for OCH200m $\left({ }^{\circ} \mathrm{C}\right.$, left) SST (central) and precipitation $\left(\mathrm{mm} \mathrm{day}^{-1}\right)$ and wind stress $\left(\mathrm{N} \mathrm{m}^{-2}\right.$, right). For the OHC and the SST, the superimposed contours are the seasonal cycle with the annual mean removed. d)-f) Differences between water hosing experiment and the control run for the variables OHC (left) SST(central) and the precipitation (shaded right) and the zonal wind stress (contour right). For d)-f) the significance has been tested with a t-test of equal means at $95 \%$ confidence level. 
a) mean Nino3

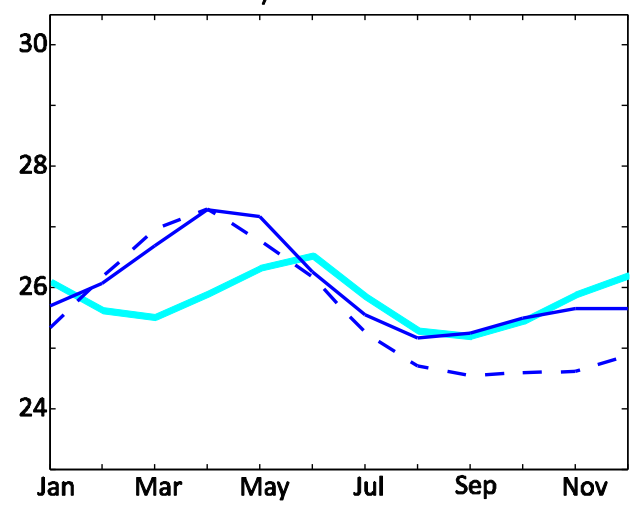

c) std Nino3

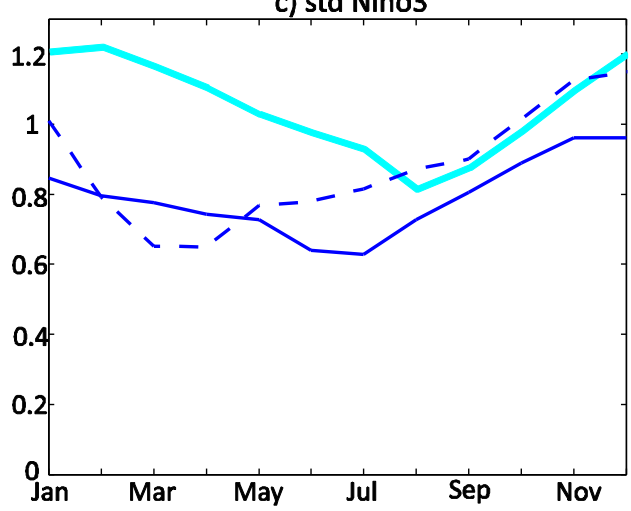

e) Ftest $99 \%$ varWat/varCtrl Nino3

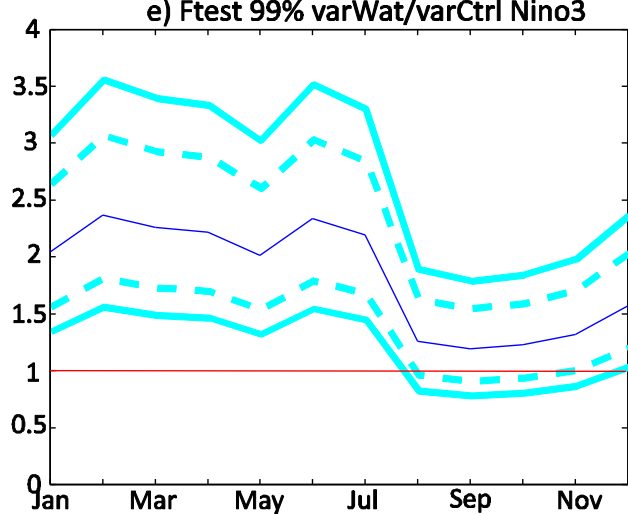

g) Power Spectrum Nino3

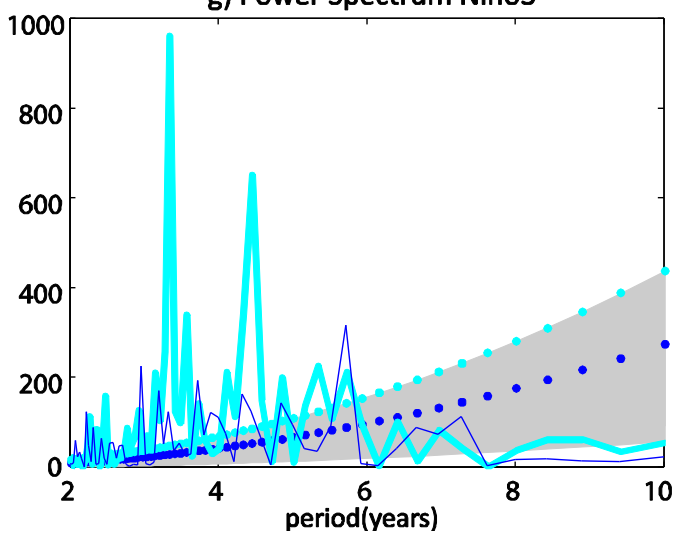

b) mean Atl3

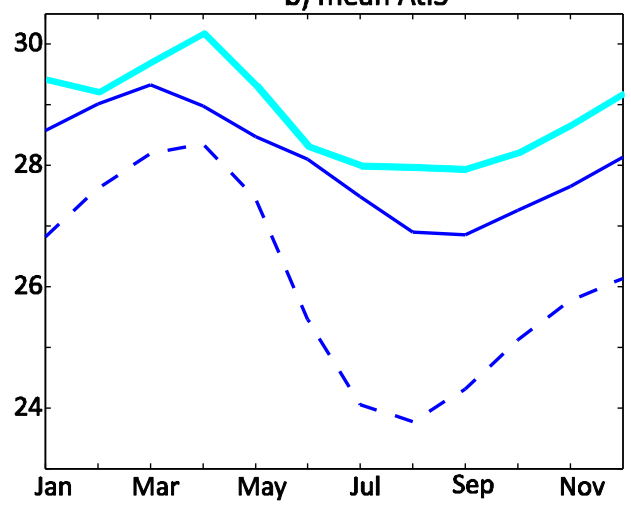

d) std Atl3
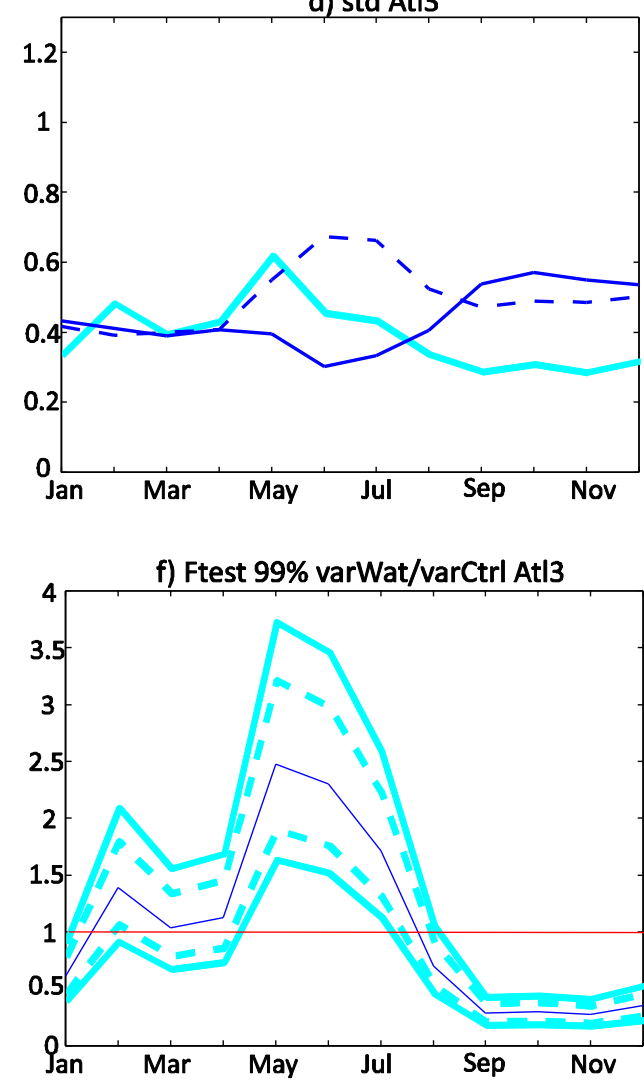

h) Power Spectrum Atl3

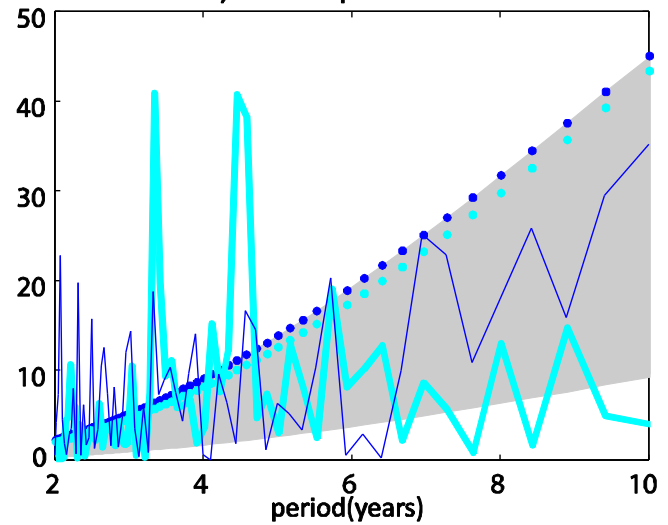

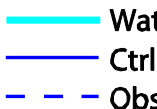

-- Obs

Figure 5 Seasonal cycle of the indexes: a) -b) Seasonal cycle mean c)-d) standard deviation $\left({ }^{\circ} \mathrm{C}\right)$, for the Niño3 (left) and Atl3 (right) index for the observations, the control run and the water hosing experiment. e)-f) Ratio variance between water hosing experiment and control run for the indexes (dark blue) and the confidence interval for a F-test with $90 \%$ (light blue-dashed) $99 \%$ (light blue-solid) of confidence level. The interval containing the unit has $\mathrm{p}=0.01$ of the variance being not equal. g)-h) Power spectrum for the annual mean of the two indexes for the control run and the water hosing experiment performed from the MultiTapper Method. Shaded areas corresponds to the confidence interval at 95\% confidence level of the spectrum of AR(1) process with characteristics of the time series. 
a) 20y running correlation At|3 JJAS lagged Nino3 CTRL 90\%

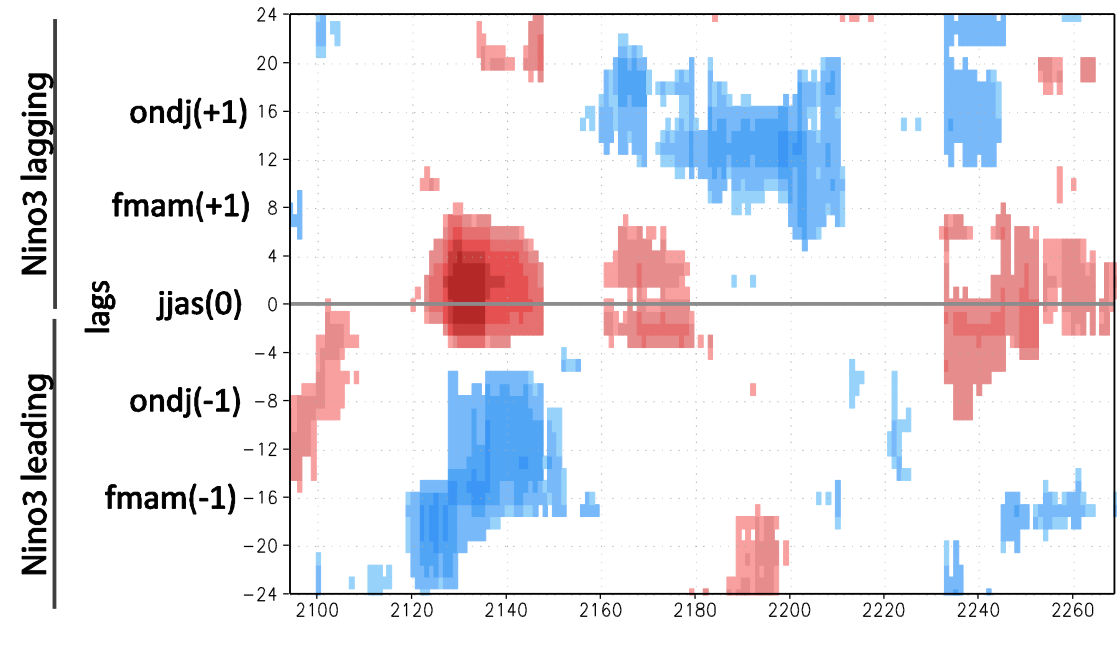

b) $20 y$ running correlation Atl3 JJAS lagged Nino3 WATHos $90 \%$

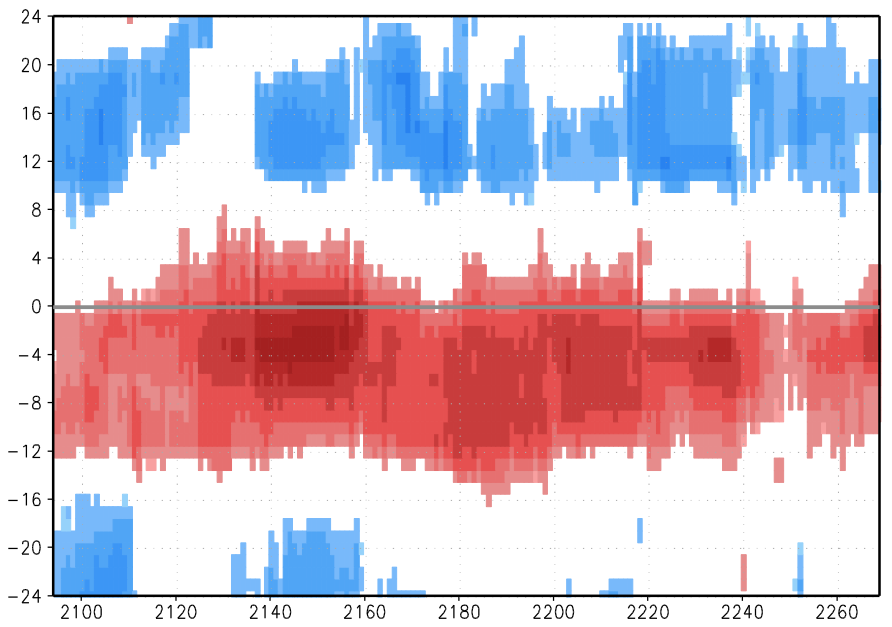

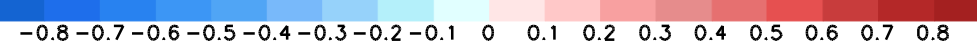

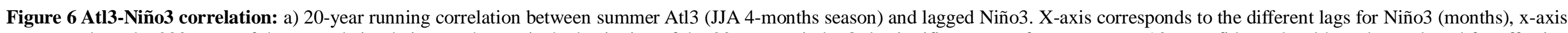

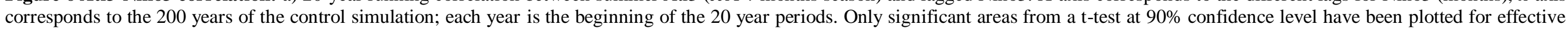
number of degrees of freedom. b) Same as a) but for the water hosing experiment. 


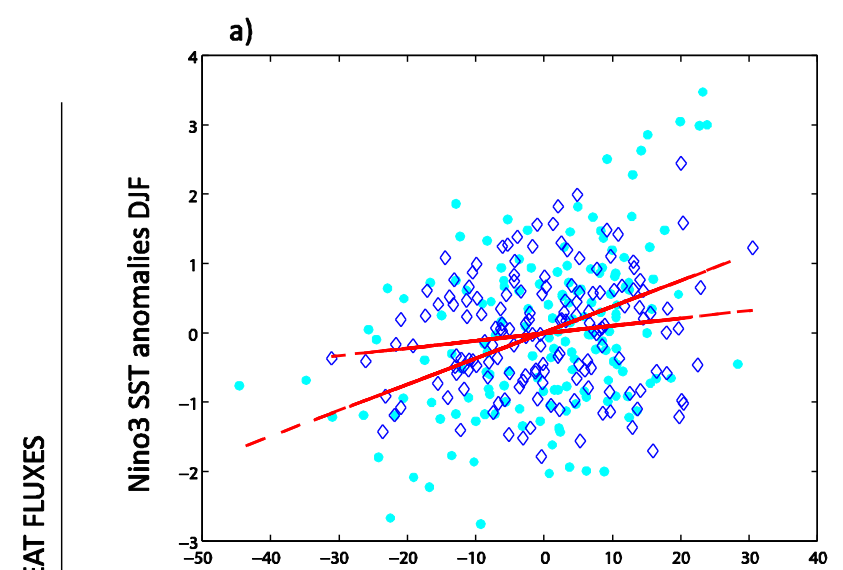

Atl3 Total HeatFlux anomalies DJF

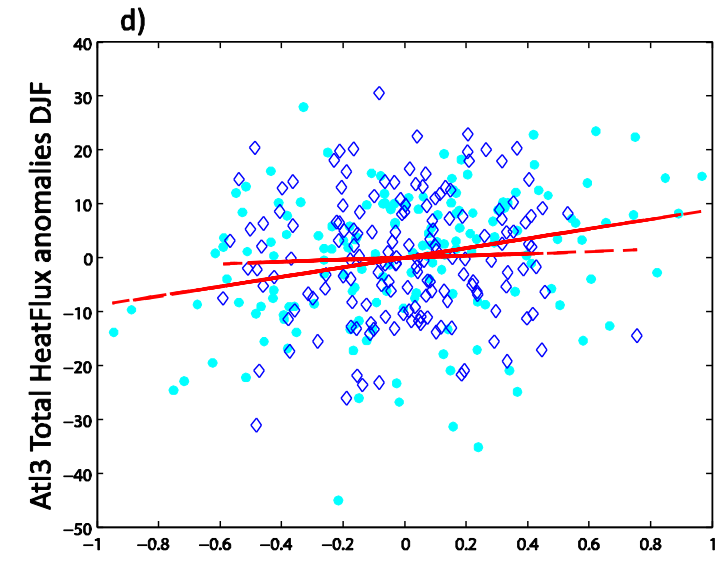

- WAT

At|3 SST anomalies MJJ

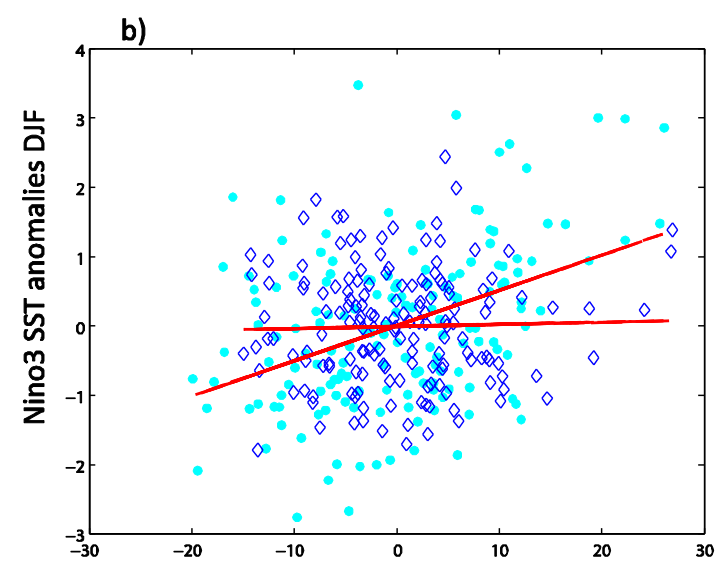

At|3 Total HeatFlux anomalies MAM

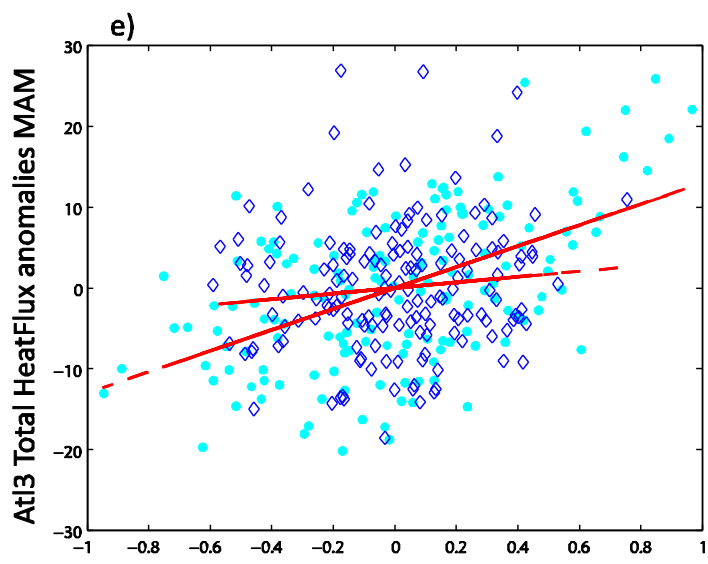

Atl3 SST anomalies MJJ

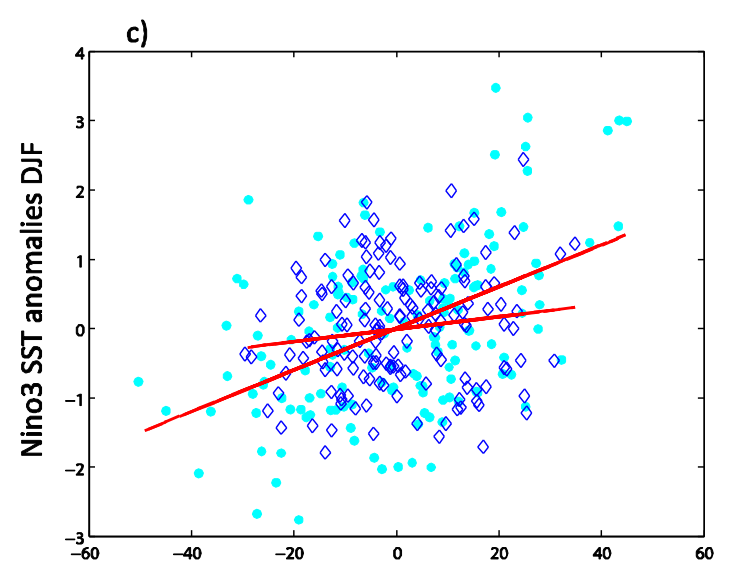

At|3 Total HeatFlux anomalies DJF+MAM

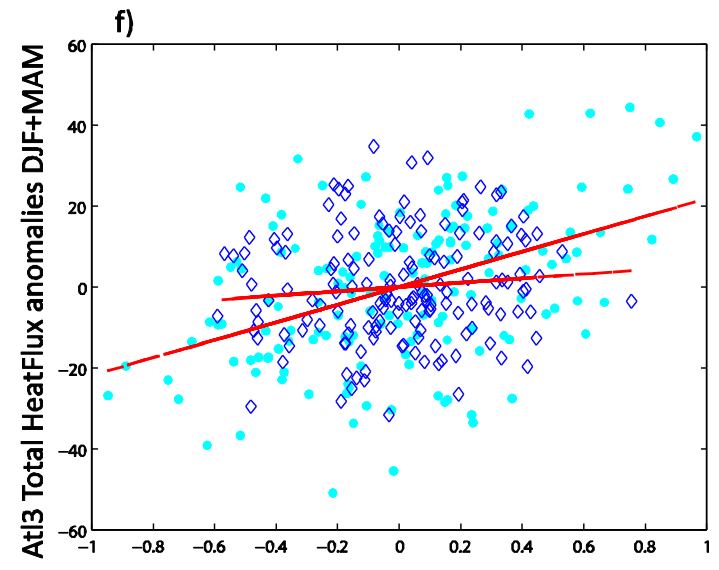

Atl3 SST anomalies MJJ

\section{Figure 7 Mechanism for spring: Scatter plots of:}

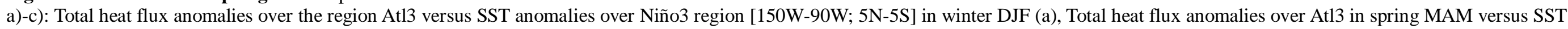
anomalies over Niño3 in winter DJF (b), Total heat flux anomalies over the Atl3 integrated from winter to spring versus SST anomalies over Niño3 in winter DJF (c).

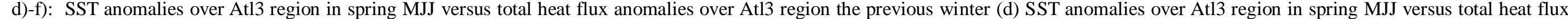

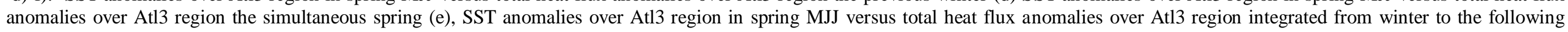
spring (f).

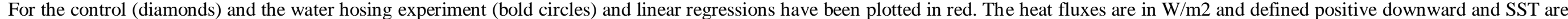
in $\mathrm{C}$. 
a) Regre Nino3DJF SST DJF (0)

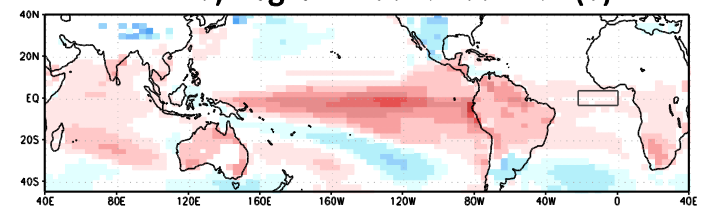

e) Regre Nino3DJF SST MAM (+1)
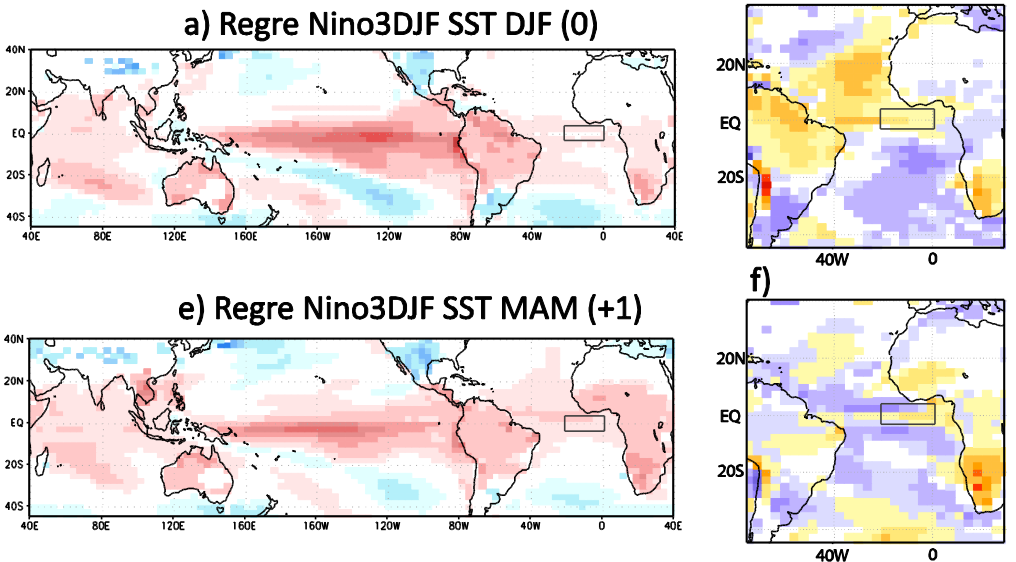

\section{f)}

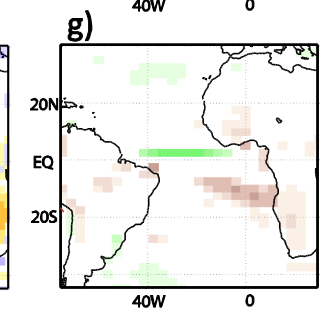

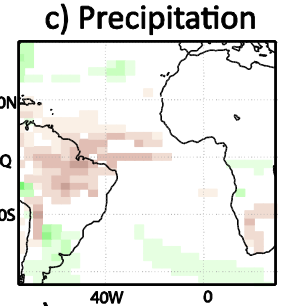

g) d) WindStress speed

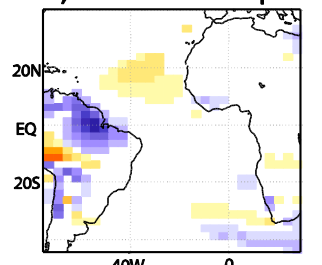

h)

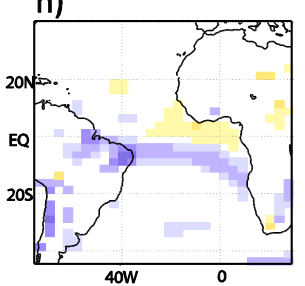

$-1.6-1.4-1.2-1-0.8-0.6-0.4-0.200 .20 .40 .60 .8 \quad 11.21 .41 .6$

Figure 8 Regression Niño3 DJF Ctrl: Regression of SST in C $\mathrm{C}(\mathrm{a}, \mathrm{e})$ Total Heat Fluxes in W/m2 positive downward (b,f) precipitation in $\mathrm{mm} /$ day and wind stress in $\mathrm{N} / \mathrm{m} 2(\mathrm{c}, \mathrm{g})$ and wind stress speed in N/m2 (d,h) onto Niño3 DJF index nonstandardized simultaneously (top) and the following spring (bottom) for the control run.

b) Total Heat Fluxes

c) Precipitation

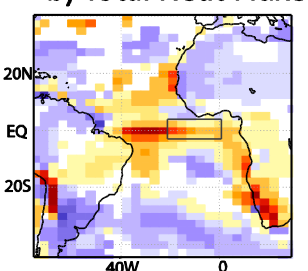

f)

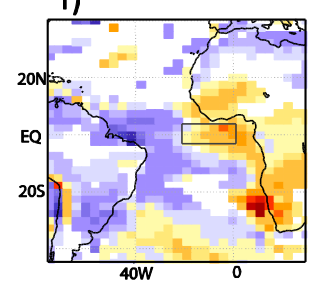

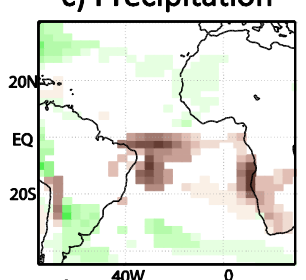

g)

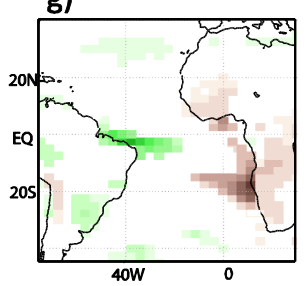

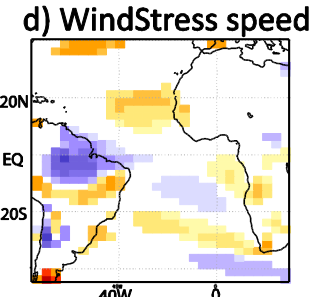

h)

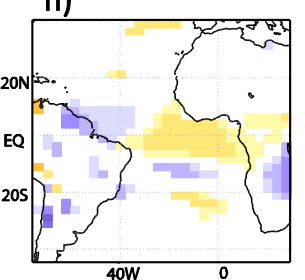

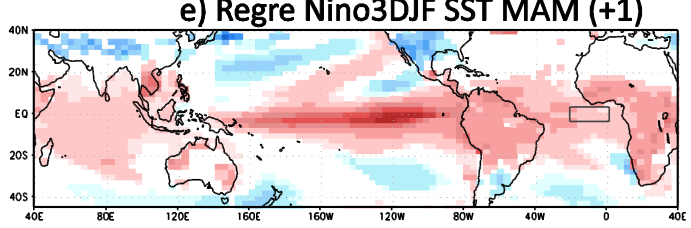

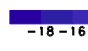

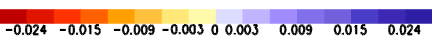

$-1.6-1.4-1.2-1-0.8-0.6-0.4-0.2 \quad 0 \quad 0.20 .40 .60 .8 \quad 11.21 .41 .6$

Figure 9 Regression Niño3 DJF Wat: Same as 7 but for the water hosing experiment

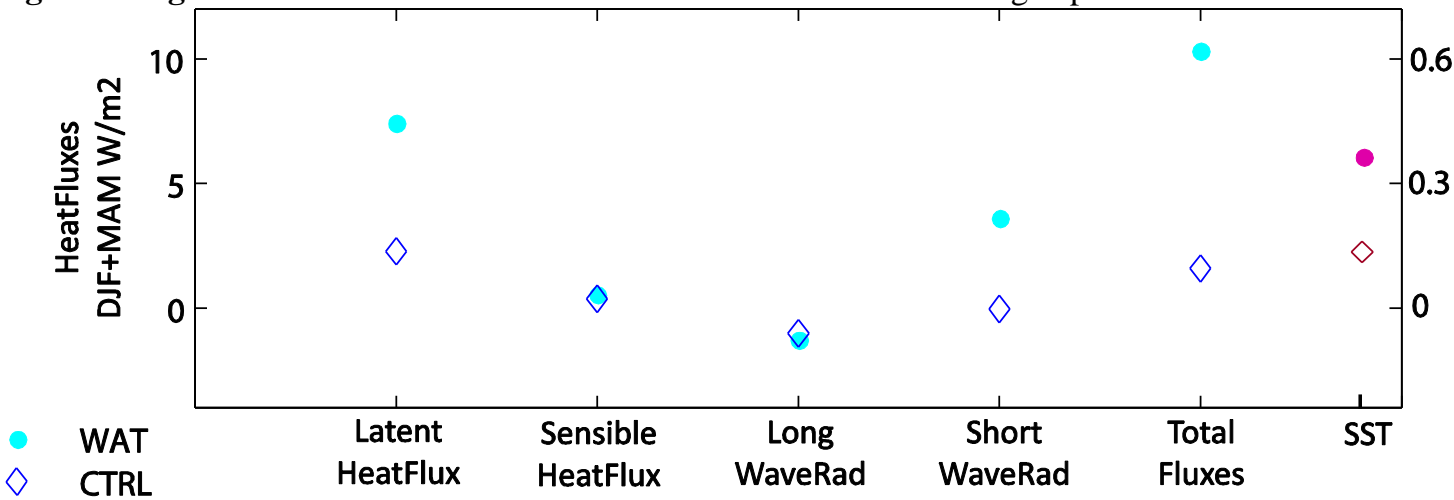

Figure 10 Regression of anomalous Heat Fluxes: Regression of anomalous heat fluxes components (in W/m2 positive downward) onto Niño3 Index DJF, integrated in time from winter to the following spring and averaged over Atl3 index region for the control (diamonds) and the water hosing experiment (bold circles). Regression of anomalous SST (in C) changes from DJF to MAM onto Niño3 index DJF is shown in red in the right side $\mathrm{x}$-axis. 

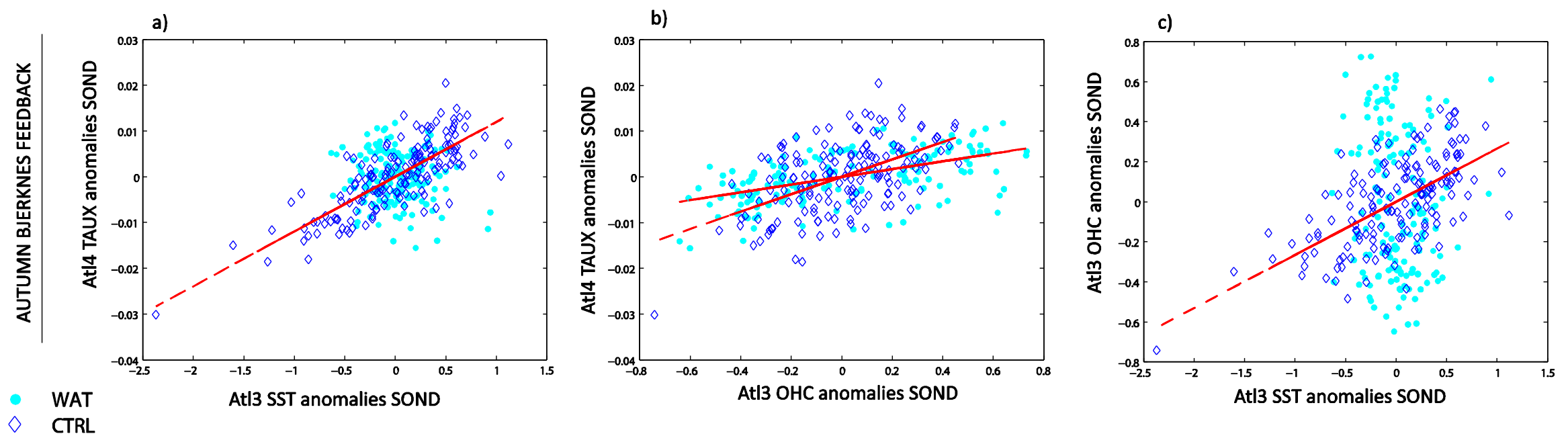

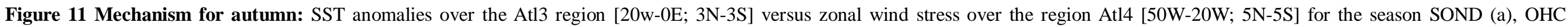

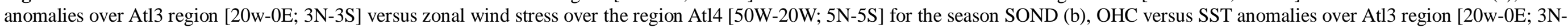

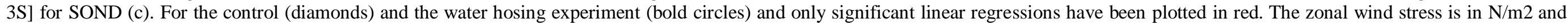
the $\mathrm{OHC}$ and SST are in C. 
a) varAMO-/varAMO+ $\mathrm{Nino} 3$

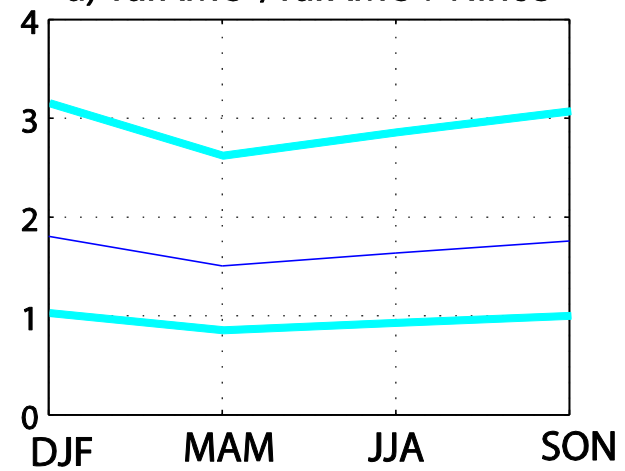

b) varAMO-/varAMO+Atl3

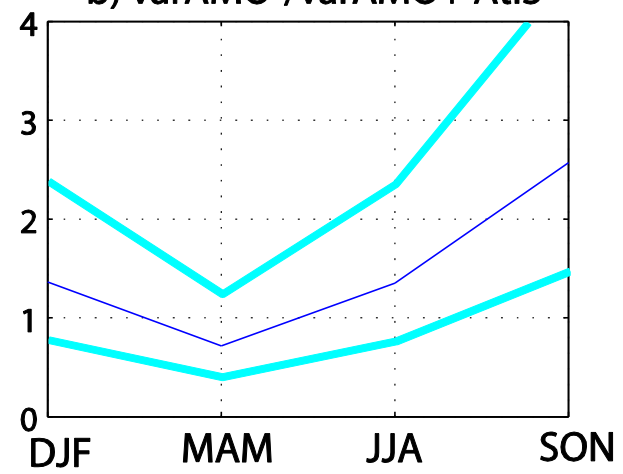

Figure 12 Variability in the observations: a) Ratio between the variance of Niño3 index for negative AMO phase (1960-1994) and the variance for positive AMO phase (1921-1959) for each season (blue line) and the confidence interval for an F-test with $90 \%$ of the confidence level (light-blue). b) Same as a) but for the Atl3 index. 
1

\begin{tabular}{|c|c|c|c|c|c|c|c|c|c|}
\hline & $\begin{array}{l}\text { SSTNino3DJF } \\
\text { HFAtl3 DJF }\end{array}$ & $\begin{array}{l}\text { SSTNino3DJF } \\
\text { HFAtl3 MAM }\end{array}$ & $\begin{array}{c}\text { SSTNino3DJF } \\
\text { HFAtl3 } \\
\text { DJF+MAM }\end{array}$ & $\begin{array}{l}\text { SSTAtl3MJJ } \\
\text { HF Atl3 DJF }\end{array}$ & $\begin{array}{c}\text { SSTAtl3MJJ } \\
\text { HF Atl3 MAM }\end{array}$ & $\begin{array}{c}\text { SSTAtl3MJJ } \\
\text { HF Atl3 } \\
\text { DJF+MAM }\end{array}$ & $\begin{array}{c}\text { TAUX Atl4 } \\
\text { SST Atl3 }\end{array}$ & $\begin{array}{c}\text { TAUX Atl4 } \\
\text { OHC Atl3 }\end{array}$ & $\begin{array}{c}\text { OHC Atl3 } \\
\text { SST Atl3 }\end{array}$ \\
\hline WAT & 0.40 & 0.41 & 0.47 & 0.27 & 0.52 & 0.45 & -0.12 & 0.54 & -0.12 \\
\hline CTRL & 0.15 & 0.03 & 0.14 & 0.04 & 0.12 & 0.10 & 0.79 & 0.53 & 0.63 \\
\hline
\end{tabular}

3 Table 1: Correlation coefficients between the different components related to the mechanisms explained in Figure 7 and Figure 11 for the water hosing experiment and the control 4 run.

\begin{tabular}{|c|c|c|c|c|c|c|c|c|c|}
\hline & $\begin{array}{l}\text { SSTNino3DJF } \\
\text { HFAtl3 DJF }\end{array}$ & $\begin{array}{l}\text { SSTNino3DJF } \\
\text { HFAtl3 MAM }\end{array}$ & $\begin{array}{c}\text { SSTNino3DJF } \\
\text { HFAtl3 } \\
\text { DJF+MAM } \\
\end{array}$ & $\begin{array}{l}\text { SSTAtl3MJJ } \\
\text { HF Atl3 DJF }\end{array}$ & $\begin{array}{c}\text { SSTAtl3MJJ } \\
\text { HF Atl3 MAM }\end{array}$ & $\begin{array}{c}\text { SSTAtl3MJJ } \\
\text { HF Atl3 } \\
\text { DJF+MAM } \\
\end{array}$ & $\begin{array}{c}\text { TAUX Atl4 } \\
\text { SST Atl3 }\end{array}$ & $\begin{array}{l}\text { TAUX Atl4 } \\
\text { OHC Atl3 }\end{array}$ & $\begin{array}{c}\text { OHC Atl3 } \\
\text { SST Atl3 }\end{array}$ \\
\hline WAT & 0.40 & 0.41 & 0.47 & 0.27 & 0.52 & 0.45 & -0.12 & 0.54 & -0.12 \\
\hline CTRL & 0.15 & 0.03 & 0.14 & 0.04 & 0.12 & 0.10 & 0.79 & 0.53 & 0.63 \\
\hline
\end{tabular}

7

8 Table 1: Correlation coefficients between the different components related to the mechanisms explained in Figure 7 and Figure 11 for the water hosing experiment and the control 9 run. 